\title{
A Conceptual Framework to Support Digital Transformation in Manufacturing Using an Integrated Business Process Management Approach
}

\author{
Javaid Butt $($ ) \\ School of Engineering and Built Environment, Anglia Ruskin University, Chelmsford CM1 1SQ, Essex, UK; \\ javaid.butt@anglia.ac.uk
}

Received: 31 May 2020; Accepted: 23 June 2020; Published: 27 June 2020

\begin{abstract}
Digital transformation is no longer a future trend, as it has become a necessity for businesses to grow and remain competitive in the market. The fourth industrial revolution, called Industry 4.0, is at the heart of this transformation, and is supporting organizations in achieving benefits that were unthinkable a few years ago. The impact of Industry 4.0 enabling technologies in the manufacturing sector is undeniable, and their correct use offers benefits such as improved productivity and asset performance, reduced inefficiencies, lower production and maintenance costs, while enhancing system agility and flexibility. However, organizations have found the move towards digital transformation extremely challenging for several reasons, including a lack of standardized implementation protocols, emphasis on the introduction of new technologies without assessing their role within the business, the compartmentalization of digital initiatives from the rest of the business, and the large-scale implementation of digitalization without a realistic view of return on investment. To instill confidence and reduce the anxiety surrounding Industry 4.0 implementation in the manufacturing sector, this paper presents a conceptual framework based on business process management (BPM). The framework is informed by a content-centric literature review of Industry 4.0 technologies, its design principles, and BPM method. This integrated framework incorporates the factors that are often overlooked during digital transformation and presents a structured methodology that can be employed by manufacturing organizations to facilitate their transition towards Industry 4.0.
\end{abstract}

Keywords: business process management; Industry 4.0; design principles; lean six sigma; change management; skills gap analysis; digital transformation

\section{Introduction}

Digital transformation is characterized by the use of emerging and frequently changing digital technologies to solve specific issues. It is quickly becoming a top priority for organizations worldwide, and, especially during the pandemic of COVID-19, the planning phases have accelerated significantly, as organizations can now practically assess the adverse impact of not having embedded digital technologies. The role of Industry 4.0, enabling technologies to support digital transformation, was an intensive research area before COVID-19, but this pandemic has expedited the efforts to ensure better strategies are available to realize the full benefits of Industry 4.0. The focus has shifted drastically from digitization (conversion of data to digital form) to digitalization that is focused on the 'organizational process' or 'business process' of the technologically-induced change within industries, organizations, and markets [1]. The digitalization of manufacturing industries has enabled new production processes using the key technology trends of Industry 4.0 and its design principles [2,3], as shown in Figure 1. 


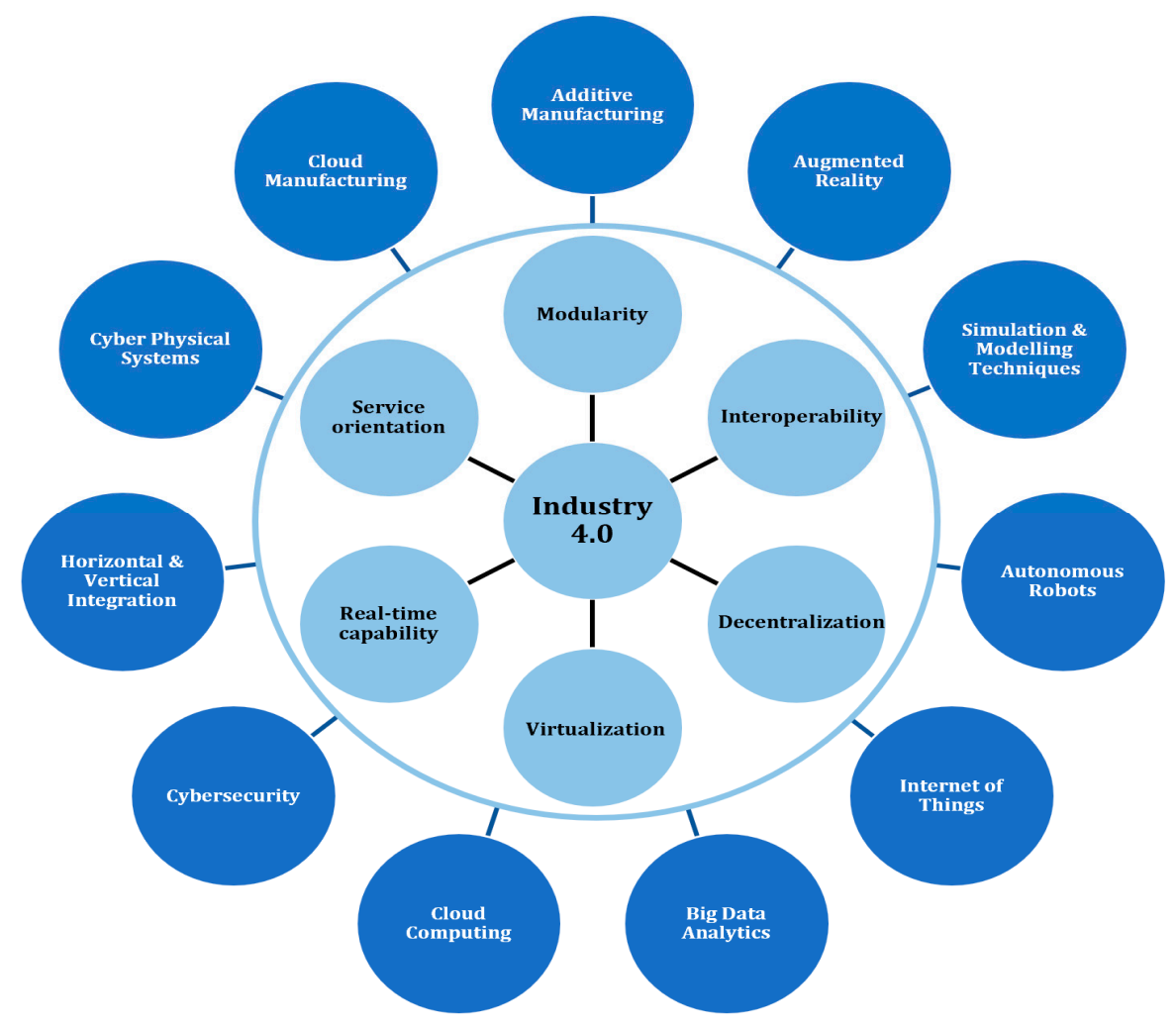

Figure 1. Industry 4.0 technology trends and design principles.

The major issues with the adoption of digital techniques and Industry 4.0 initiatives can be summarized as a lack of readiness, with organizations not being able to realistically perceive the benefits on offer [4,5]. Technology and innovation management are useful organizational strategies, but the problem comes when there is low awareness or lack of knowledge pertaining to the specific Industry 4.0 technologies that require management [6,7]. People, in general, fear the unknown and resist change. These anxieties become amplified when the positive impacts of Industry 4.0 come to light. The use of Industry 4.0 enabling technologies has resulted in improved productivity and efficiency, increased knowledge sharing and collaborative working, flexibility and agility, easier compliance with regulations, better customer experience, reduced costs, and higher revenues [8]. This has fascinated some, but has scared most, as there is uncertainty around job security and future implications for people and organizations alike. Therefore, it becomes crucial to devise an organization-wide strategy for digital transformation. Unfortunately, the role of digital technologies in business transformation is under-investigated [9]. The main issues include an inability to correctly identify the targeted performance objectives and a lack of leadership capacities. This results in Industry 4.0 projects being designed as cost-driven initiatives that are unable to provide or support any real business model transformation [10,11]. There are concentrated efforts where digital technologies are being used to transform manufacturing value chains from research and development, supply chain, and factory operations to marketing, sales, and service. This requires processing large data sets for informed decision making using the Internet of Things (Section 2.5) and big data analytics (Section 2.6). Digital connectivity among designers, managers, workers, consumers, and physical industrial assets can unlock enormous value and provide significant benefits [12]. To ensure connectivity, it is critical to understand the interface between different business processes, to correctly identify the required Industry 4.0 enabling technologies and ensure the development of an organization-wide approach that can add value for customers and for internal processes $[13,14]$.

Governments of different countries have also taken notice of the impact of Industry 4.0 and have developed plans to take advantage of the opportunities. There is, however, a difference in 
approaches. For example, European countries and the USA are focused on developing business and standardization models [15-18], and countries like Japan, Germany, and China are implementing digitalization, to increase efficiency and product quality, as well as to reduce costs $[19,20]$. On the other hand, the Australian government has signed a cooperation agreement with Germany's Industrie 4.0 platform, to research reference architectures, standards, test laboratories, as well as the development of education and training resources [21]. Such efforts indicate the need for developing strategic and technological roadmaps that can facilitate the digital transformation of organizations. There are several examples in the literature where strategic plans have been conceptualized, developed, and implemented to varying degrees of success, based on lean six sigma-models [22,23], business process management models [24,25], a maturity level-based model [26], and an outcome-based business model [27]. However, they lack the emphasis on some key aspects, such as the streamlining of business processes after implementation, workforce skills gap identification, and effective change management protocols.

This paper aims to offer an integrative business process management framework that can be used as a reference model by academics and manufacturing organizations, in their journey towards a successful transition from traditional manufacturing to Industry 4.0. It incorporates the key factors that are often overlooked in Industry 4.0 implementation and presents a synergistic plan to address them. Having a deep understanding of Industry 4.0 enabling technologies and its design principles is a prerequisite for devising an implementation plan. Therefore, Section 2 presents a review of Industry 4.0 key technology trends and Section 3 presents an overview of its design principles. Section 4 is focused on business process management whereas Section 5 presents the conceptualization and complete breakdown of the proposed integrated business process management framework. The discussion in Section 5 is centered around the phases and the associated challenges that manufacturing organizations may face while transitioning into Industry 4.0 — enabled digital enterprises.

\section{Key Technology Trends of Industry 4.0}

\subsection{Additive Manufacturing}

This is an umbrella term that encompasses a group of technologies capable of manufacturing three-dimensional objects by adding layers on top of each other, using different materials based on a computer-aided design file of a product [28-32]. Additive manufacturing (AM) technologies have become the top choice for the manufacture of complex geometries, with intricate features in several industries, including automotive, aerospace, and medical $[33,34]$. AM methods excel at the development of porous/hollow parts with improved aesthetics, increased surface area, heat transfer (lattice structures), and mass customisation [35,36]. Furthermore, numerical simulation methods have helped in identifying the optimal processing parameters that can help in the production of bespoke products efficiently [37-39]. The impact of AM can be evidenced through the response of the AM community to support medical professionals, by providing products in mass quantities ranging from PPE such as face masks, and medical device components such as ventilator valves and swab testing kits, as well as ecosystem components such as hands-free door openers. AM has emerged as a supply chain enabler during this crisis, by not only providing essential products, but also by connecting designers and manufacturers to healthcare professionals through scientific data sharing protocols [40]. AM is a key player when it comes to product customization, design flexibility, time and cost-effectiveness, and reducing the total number of parts through part consolidation [41].

\subsection{Augmented Reality}

The development activities of augmented reality (AR) date back to the 1960s, when researchers developed a see-through display to show 3D graphics in a helmet [42]. AR is often used in conjunction with virtual reality (VR) to offer unique solutions [43-45]. AR augments 3D graphics in a real-world environment, whereas VR is an artificial environment that is created with software and presented to the user in a way that the user accepts it as a real environment [46]. AR is being adopted at 
an accelerated rate by the manufacturing sector for a multitude of reasons. Commonly used AR protocols include AR markers [47] and mobile devices [48], as well as hologram [49], tracking [50], and interaction technologies [51]. AR is benefitting the manufacturing sector by providing better insights for product development, equipment maintenance, workforce training, production floor issues, process flow, and quality assurance $[52,53]$. AR has also been widely adopted by the medical sector. The work done by Wake et al. [54] in the field of medicine and healthcare showed a workflow for additive manufacturing a kidney and developing AR models, using radiology examination and image segmentation. An AR kidney model was created using Unity 3D software and deployed to a Microsoft HoloLens. The AM kidney and AR models were used preoperatively and intraoperatively to assist in robotic partial nephrectomy. This technique demonstrated the reliability and feasibility of the AM/AR combination that can influence surgical planning decisions for better results. The use of AR has also benefitted the education, automotive, retail, finance, and tourism sectors [55-58].

\subsection{Simulation and Modelling Techniques}

They serve an extremely useful purpose by providing a visual representation of a product or process, and showing the effects of different conditions in a virtual environment. They not only save costs by optimizing the geometry or process flow features, but can also predict future states based on different mathematical models. Simulations can be used for a product, process, or process flow, and there are several software packages available for them. Products and manufacturing processes are normally simulated based on the finite element method, finite volume method, and discrete element method. Software packages capable of using such methods include CAEplex, MATLAB, Ansys, OpenFOAM, and EMS. On the other hand, manufacturing-process-flow simulation packages are based on various modeling paradigms, including process-centric, systems dynamics, Petri net, Monte Carlo simulations, and agent-based. These packages include, but are not limited to, WITNESS, AnyLogic, FlexSim, Simio, and Simul8 Professional. They can provide animated and interactive models to replicate the operation of an existing or proposed production facility. They can help solve common manufacturing challenges that include assessing the impact of investment, production planning, optimization, and scheduling, facility designing, manufacturing capability planning, bottleneck analysis, and resource allocation [59-61].

\subsection{Autonomous Robots}

The demand for industrial robots in manufacturing has been on the rise for several years now because of their benefits e.g., lower defect rate, higher quality, enhanced reliability, reduced waste, and better floor space utilization, making them indispensable to world-class manufacturers [62]. This has also given rise to 'cobots', or collaborative robots that work closely with humans and augment their capabilities. According to the International Federation of Robotics [63], there are four types of collaborative manufacturing applications, i.e., co-existence (human and robot work together, but no shared space), sequential collaboration (human and robot work together on a part separately, but not at the same time), co-operation (human and robot operating at the same time on a part or machine), and responsive collaboration (robot responds to the human movements in real-time). Cobots are designed to fill the gaps between conventional robots and human specialists leading to new territories for automation. Cobots are intended to work in manners like people, with the additional capacity to analyze and transmit information [64]. In Industry 4.0, robots and people work collaboratively on interlinking tasks, by utilizing smart sensor human-machine interfaces. The utilization of robots is extending to incorporate different capacities, such as manufacturing, coordination, data management, remote access, and control [65]. These are extremely useful features that offer flexibility to the users and allow for the seamless integration of the physical equipment with digital software tools [66]. 


\subsection{Internet of Things}

Internet of Things (IoT) is a system of interconnected devices implanted with sensors, software, and electronics to initiate the exchange and collation of data [67]. In the manufacturing industry, it is referred to as the Industrial Internet of Things (IIoT), which facilitates communication among people, products, and machines. Manufacturers are attaching sensors to machines, and other physical assets on the production floor, to collate data that influence decisions in real-time and lead to increased efficiency as well as productivity [68]. The interconnectedness of different devices allows for a better user experience and helps in effective decision making [69]. IIoT systems are conceived as a layered modular architecture of digital technology with four layers, i.e., device, network, service, and content. The device layer refers to sensors or machines. The network layer comprises physical network buses, cloud computing, and communication protocols. The service layer manipulates and combines the data into information that can be displayed, and the content layer refers to the user interface devices, such as tablets and screens [70]. The enormous data captured through IIoT helps organizations in establishing clear objectives and enables them in understanding their systems better, by providing insights that were scarce before. It can create a digital network that keeps the entire organization connected, thus promoting collaboration and enabling the use of other key Industry 4.0 technologies effectively [71]. The rise of $5 \mathrm{G}$ has also boosted the adoption of IIoT, as the advantages will increase exponentially. 5G enabled IIoT systems will accelerate the realization of Industry 4.0, with high-speed, low-latency, and large-volume data transfers [72].

\subsection{Big Data Analytics}

The copious amounts of data collated by IIoT need to be analyzed through protocols that can help make sense of the data and use it for decision making. This is where big data analytics (BDA) come into play. 'Big data' refers to a collection of massive data sets that cannot be analyzed through conventional means. There are four types of data, i.e., structured, semi-structured, quasi-structured, and unstructured. This is also the order in which the amount of data and complexity in analysis increases drastically [73]. Based on the data, four types of analytics can be performed. The first is descriptive, that provides an effective visualization of the current business. The second is diagnostic, that helps to identify the causes of problems. Predictive is the third, that makes use of historical data and algorithms to predict future business needs. The last is prescriptive, that recommends actions and strategies based on advanced analytical tools [74]. Different BDA tools are available on the market (e.g., Xplenty, Skytree, Talend, Lumify); they can provide a meaningful analysis of a large set of data. BDA can enable manufacturers to improve their asset efficiency and performance, enhance product customization, better administrate predictive maintenance and prevent asset breakdowns, as well as streamline production processes and supply chain management initiatives more effectively [75].

\subsection{Cloud Computing}

Data collation through IIoT and analysis through BDA require both hardware and software capabilities for data processing. These costs can limit the applicability of Industry 4.0 technologies, and cloud computing (CC) can help alleviate some of that burden by removing the need for sophisticated hardware and undertaking data analysis over cloud servers. The U.S. National Institute of Standards and Technology (NIST) defined cloud computing as a model for enabling convenient, on-demand network access to a shared pool of configurable computing resources (e.g., networks, servers, storage, applications, and services) that can be rapidly provisioned and released with minimal management effort or cloud provider interaction [76]. Organizations are rapidly shifting their IT resources to $\mathrm{CC}$, due to the benefits on offer, including reduced capital costs, global scale, high speed, reliability, enhanced productivity, performance, and security [77]. CC operates in four different types, i.e., public cloud (third party cloud service providers), private cloud (resources used exclusively by a single organization), hybrid cloud (a combination of public and private), and community cloud (shared 
by several organizations) [78]. CC enables the integration of distributed manufacturing resources and the establishment of a collaborative and flexible infrastructure across geographically distributed manufacturing and service sites [79]. This could lead to cloud manufacturing being the next generation manufacturing paradigm [80].

\subsection{Cybersecurity}

The flow of enormous data sets in and out of an organization over the Internet makes cybersecurity (CS) a key element of Industry 4.0. There is a growing demand to secure critical industrial frameworks and manufacturing lines from CS threats, to protect interconnected systems. Data can be of different types, ranging from individual data to production floor plans, and new product designs to future initiatives. It is critical for some sectors (e.g., defense ministry) to ensure that their data do not fall into the wrong hands, as they can be misused on a public forum or can sabotage the business. Theft of individual data from the databases of organizations is also quite common. Prime examples are the cases of Facebook [81] and Cambridge Analytica [82]. Therefore, there are data protection rules all over the world, such as the General Data Protection Regulation (GDPR) from the European Union and the UK Data Protection Act 2018. They outline the regulations for personal data handling and precautionary measures. There is also a need for the standardization of CS protocols, to instill confidence in a user organization. The most common ones are ISO/IEC 27001 and 27002, part of the ISO/IEC 27000 family of standards published by the International Organization for Standardization and the International Electrotechnical Commission [83].

\subsection{Horizontal and Vertical Integration}

Horizontal and vertical integration aims to develop organization-wide strategies for information sharing, to create the basis for an automated supply and value chain. Horizontal integration is about digitalization across the full value and supply chain, focusing on data exchanges and connected information systems. It allows for the seamless integration of IT systems and information flows across production and business planning procedures, that range from suppliers of materials and utilities to distributors and customers [84]. Horizontal integration helps with horizontal coordination, collaboration, cost savings, value creation, speed, and the possibilities to create horizontal ecosystems of value, based on information. On the other hand, vertical integration creates a comprehensive solution by integrating IT systems at various hierarchical production and manufacturing levels. These hierarchical levels include the field level (interfacing with the production process via sensors and actuators), the control level (regulation of both machines and systems), the production process level (to be monitored and controlled), the operations level (production planning and quality management) and the enterprise planning level (order management and processing). Combining these two is key to a truly digitized future for organizations $[85,86]$.

\subsection{Cyber-Physical Systems}

Cyber-physical systems (CPS) are systems of collaborating computational entities that are in intensive connection with the surrounding physical world and its on-going processes, providing and using data-accessing, as well as data-processing services available on the Internet, concurrently [87]. CPS is usually based on a 5C architecture of connection, conversion, cyber, cognition, and configuration [88]. However, it has been extended to include customer, content, and coalition [89]. CPS is interconnected between the physical factory floor and the cyber computational space. With the help of BDA, they help in comprehending trends and supporting informed decision making in real-time [90]. CPS is the future of the manufacturing sector, as it can work for products and processes alike. The challenges lie in the use of appropriate tools and analysis techniques that can provide useful insights to develop an action plan. CPS mainly comprises three components i.e., communication and computation as well as control, and handling as well as monitoring [91,92]. The use of CPS aims to increase the implementation of large-scale systems, improving the adaptability, autonomy, efficiency, 
functionality, reliability, safety, and usability of such systems [93]. These systems are being applied to diverse areas, such as cyber manufacturing, smart energy systems, and smart factory $[94,95]$.

\subsection{Cyber Manufacturing}

Cyber manufacturing (CM) is a concept derived from CPS and refers to a system that offers an information-transparent environment, to facilitate asset management, provide reconfigurability, and maintain productivity. It involves data conversion from interconnected systems into predictive and prescriptive operations to achieve resilient performance [96]. The enabling technologies of CM include IoT, BDA, and CPS. Its challenges include a lack of standardization protocols for seamless connectivity [97], extracting actionable data to avoid disconnected analytics [98], and CS [99]. The benefits on offer from CM are quite significant, especially for organizations with multi-scale, complex, and networked assets, as they can maintain productivity by reducing unexpected downtime and reconfiguring production assets based on their health status, leading to resilient manufacturing systems. Manufacturing services are communicated to both users and consumers, who access those services via various channels [100]. Manufacturing software should be deployed in the cloud to enable the offering of such services. Manufacturing services should be deployed in various models, including the public, private, community, and hybrid clouds (Section 2.7). Each cloud can provide customers with different services. For example, the customer can find the required product offers in a public cloud, and an organization employee can find services and infrastructure provided from their organization or its specified service provider in a private cloud. BDA will be used to offer the best services to satisfy consumer requirements and expectations [101]. The use of CPS in manufacturing is referred to as CPPS (cyber-physical production systems), and this concept is slowly gaining momentum from academia and industries alike [102,103].

\section{Industry 4.0 Design Principles}

\subsection{Modularity}

It refers to the design of system components and is characterized by the capability of system components to be removed or added in an efficient manner [104], leading to agile manufacturing systems rather than linear ones [105]. This feature is extremely beneficial when dealing with fluctuating production orders, customized product development, or incorporating new technologies [106]. System components are loosely coupled and can be reconfigured on a plug-and-play principle [107]. This design feature allows the system to rapidly integrate required modules to quickly respond to customers' requirements and overcome internal system malfunctions by enabling the interchangeability of modules [108]. Modularity builds on the agile supply chain, flexible material flow systems, modular decision-making procedures, and flexible processes [109], by allowing the application of module machine tools, workstations, material handling equipment, and reconfigurable tools [101].

\subsection{Interoperability}

Embracing and implementing new technologies will have limited impact if contextual information cannot be shared among machines, objects, and people. Establishing connectivity through the use of digital techniques such as IoT, BDA, and cloud computing should allow an open exchange of information between systems, to help businesses reduce the costs of information collection and management [110]. This aspect has paved the way for the design principle of interoperability that is defined as the exchange of data among systems through the use of Industry 4.0 enabling technologies [2]. Interoperability in Industry 4.0 can be defined in four different levels, i.e., operational, semantic, systematical, and technical interoperability [111]. Interoperability is different from data standardization, as it focuses on contextual information and the interaction of different system components to communicate and understand the information for decision making [112]. Interoperability enables applications, such as standard and 
secure communication, sharing meaningful information, collaborative behaviour, embedded systems, and CPS operation [101].

\subsection{Decentralization}

This is a popular concept that organizations have been embracing for years and allows independent operations as well as autonomous decisions through various components in a system rather than a centralized system, enabling flexibility and adaptability [104]. These decisions are made in real-time and in compliance with the organizational objectives. CPS and digital twins are among the key enablers of decentralization [113]. Organizations benefit from decentralization, as employees only need to interfere in case of a problem, and they can spend their time on other productive activities, which will increase the overall effectiveness in responding to individual and customized orders [114,115]. Cloud computing can be considered as a form of decentralization [116], and additive manufacturing systems have been enabling organizations to operate small, decentralized factories for years. This aspect has come to the forefront during the COVID-19 pandemic, where AM systems from large, medium, and small organizations alike have been used to manufacture large quantities of face shields, ventilator valves, and hands-free door openers [40]. Modularity enables the modular and decentralized control architecture for machines and tools through embedded computer systems, leading to the development of smart products [101].

\subsection{Virtualization}

This design principle refers to two different scenarios. First is the case where one virtual resource is created from multiple physical resources, and in the second scenario, many virtual resources are created from one or more physical resources. In the former, the physical assets are simulated through the development of component and system-based digital twins or CPS [117]. In the latter, the software is used to divide one physical server into multiple virtual servers that act like unique physical devices. Digital twins can serve a variety of purposes, e.g., performance optimization, visualizing different scenarios, and real-time control. This provides the benefits of extending equipment life, identifying system inefficiencies, and reducing operational, as well as maintenance, costs [118,119]. CPS also allows the same opportunities by collating sensor data, analysis, and decision making through the use of decentralized control circuits [120]. Besides, virtual reality (VR) has also proven to be a useful tool for workforce training, improving their performance, guiding maintenance, and assembly tasks [121,122]. A combination of VR and AR with mobile devices provides stakeholders (employees and customers) with more insight into the detailed design of products and allows better process tracking [123-125]. Virtualization enables virtual system building, factory data virtualization, virtual modelling language, and virtual interfacing with digital twins as well as CPS [101].

\subsection{Real-Time Capability}

One of the main features of Industry 4.0 is the agility of operations that cannot happen without real-time data collation and analysis supporting decision making, and even real-time cyber-security attack detection [126]. It is also related to the system's ability to respond to internal (machine malfunctions) and external (customer orders) changes promptly, by quickly collecting and analysing the available data in real-time [127]. Such a capability allows managers to track the business (through trends and micro-trends), identify areas of improvements (through continuous data analysis), respond to failures (through informed decision making), and monitor performance (through data collation). Having modularity within the system is important, as changes could indicate a decision to focus on some production units, or could detect an abnormality in some others. In this case, the systems should be able to recover based on the data, by shutting the affected modular units and continuing operations with the rest until the problem is fixed [128]. Real-time capability supports the other design principles and can be considered as an essential design principle when moving towards digital transformation. 


\subsection{Service Orientation}

Businesses can meet customer demands better through real-time capability (allowing data processing through BDA) and interoperability (allowing a free flow of information). As a result, businesses can tailor their services based on changing customer needs, thus, shifting the focus from products to customers and from mass production to tailored services. Service orientation allows manufacturing organizations to sell both their products and services to customers. In addition to selling products, organizations can sell their services to make more profit through an integrated product-service model [129]. A prime example is the use of AM systems by AM companies to meet the demand for personal protective equipment and medical devices to support medical professionals to fight COVID-19 [40]. Such a model helps organizations to outsource some of their processes and focus on their main business processes [130]. This strategy will encourage innovation at a rapid rate, as the focus would be concentrated and not dispersed. As a result, the manufacturing industry will be in a position to sell its main business process(es) as a service to another industry. CM is a good example that describes an infrastructure where the Internet is used as a medium for offering and selling services and cloud computing playing a crucial part in enabling the on-demand provision of services [131].

\section{Business Process Management}

A business process is a set of related functions (and sub-functions) in a specific sequence performed by people or machinery that can deliver value to an internal or external customer. Business processes are present at all organizational levels and not all of them are visible to external customers. A business process can be represented by flowcharts showing the flow of activities. Managing business processes effectively leads to higher productivity and efficiency of the business. There are different approaches to defining the types of business processes. For example, Rosing, Von Scheel, and Scheer [132] classified business processes into main/core processes (focus on delivering value), management processes (focus on overseeing main processes), and supporting processes (focus on supporting the main processes), as shown in Figure 2. On the other hand, Kirchmer [133] showed a slight variation and classified them as operational processes (primary business processes that create value), management processes (focus on ensuring operational processes are conducted correctly), and governance processes (ensure compliance with legal guidelines).

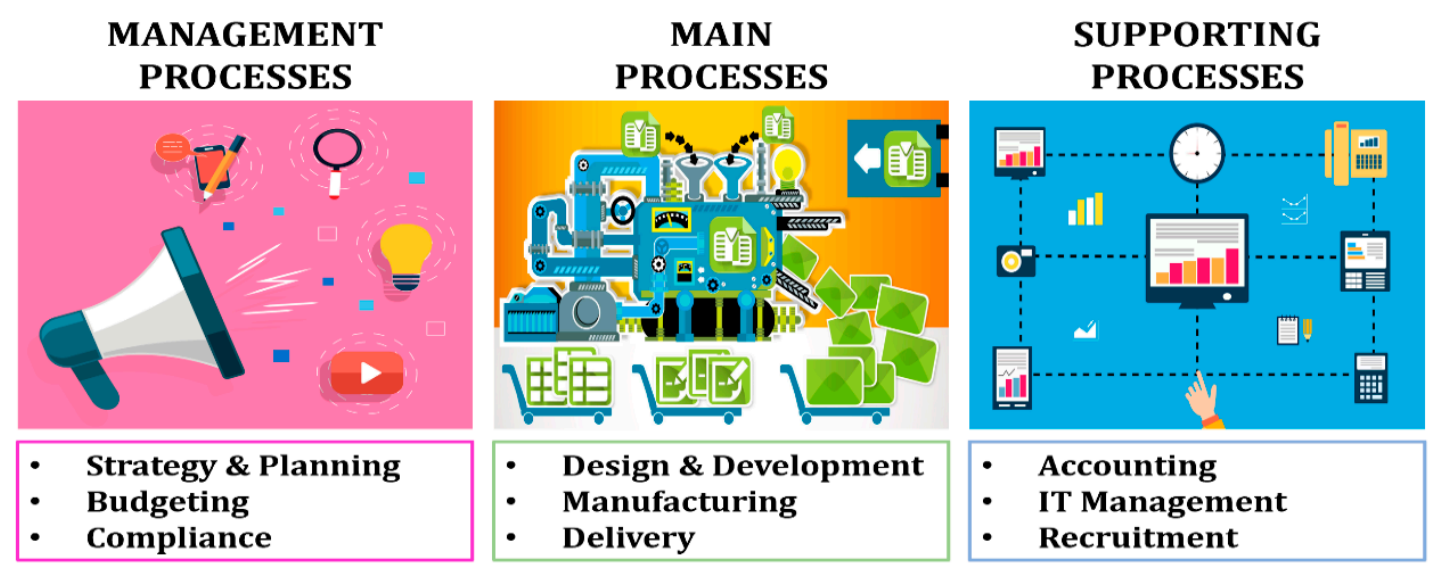

Figure 2. Different types of business processes.

The smooth running of business processes is essential for a successful business. In that context, two business management strategies are quite popular, i.e., business process reengineering (BPR) and business process management (BPM). BPR was introduced in the early 1990s and aimed to help organizations fundamentally rethink the workflow of their business processes and incorporate radical changes to increase their efficiency and productivity, improve customer service, and reduce operational costs $[134,135]$. Despite the number of definitions in the literature, some shared elements 
can be identified, e.g., radical change, dramatic performance improvements, high potential business benefits, process-based organizations, customer orientation, information technology as an enabler, rapid pace of change, and high risks [136,137]. This approach provided some benefits, but was faced with criticism because of its inability to validate its assumptions. For example, it assumes that the ineffectiveness of an organization stems from its business processes, but does not offer any means of validating that. Furthermore, the focus on always making a radical change and completely disregarding the existing process can have serious consequences. BPR was implemented with an ulterior motive in the 1990s, with organizations viewing it as a means of formally downsizing and laying-off employees to remain competitive in the market [138]. BPR was not aimed at only radical changes, but can incorporate incremental improvements as well, depending on the nature of the problem at hand [139]. The methodology is still being used with good effect; even aiding digital transformation as IT (information technology) is considered as one of its key enablers. Qu, et al. [140] used BPR to strategically enhance the adaptability and functional integrity of an enterprise information system, to meet the demands of smart manufacturing systems.

On the other hand, BPM is a management discipline that provides governance for a process-oriented organization through business process modelling, execution, and evaluation, with the goal of agility and operational performance [141]. It involves the use of several methods, policies, metrics, management practices, and software tools, to monitor and continuously improve an organization's business processes. Some of its benefits to an organization are shown in Figure 3. There are six core elements that are critical to the success of BPM initiatives, and these are strategic alignment, governance, methods, information technology, people, and culture [142]. Strategic alignment refers to aligning the BPM with the overall strategy of the organization rather than detached from it. Governance establishes appropriate and transparent accountability in terms of roles and responsibilities, with a focus on decision-making and reward processes. Methods denote the set of tools and techniques that support and enable BPM activities. Six sigma is a popular and useful approach for BPM comprising DMAIC (define, measure, analyze, improve, control) and DFSS (Design for Six Sigma) approaches [143]. IT is a key enabler of BPM, like BPR, and involves the use of software tools to support BPM initiatives. People represent the group of individuals who continually enhance and apply their process and process management skills, as well as knowledge to improve business processes. Culture incorporates the collective values and beliefs of the organization. These elements should be at the heart of every BPM initiative. BPM does not contain itself in soils of singular business processes, but breaks down barriers among different departments to establish an end-to-end business strategy. It is a powerful approach that has been providing benefits to organizations and governments by focusing on operational processes and knowledge representation $[24,25]$. However, its incorrect implementation can also lead to failures, with some of them highlighted in Figure 4.

With the rapid shift towards Industry 4.0 for business processes, BPM has been a powerful ally in supporting its adoption. The emerging IoT poses a significant challenge for organizations to control and manage the flow of information through a large number of devices [144]. To cope with this, a new direction known as BPM Everywhere (BPME) shows promise as a way of blending traditional process techniques, with additional capabilities to automate the handling of all the independent devices. BPME aims to leverage traditional business process modelling techniques, together with process mining and process analytics, to automate and distribute the activities of discovering, measuring, and improving the business processes [145]. The rising number of technical contributions using IoT shows that technologies are evolving, and, from a BPM perspective, value creation from the IoT application to technological revitalizations is pivotal [146]. There are many examples in the literature of BPM being informed by Industry 4.0 technologies and is used as an enabler for Industry 4.0 [147-151]. Suffice to say, BPM will be a key player in the digital transformation journey of organizations worldwide. 


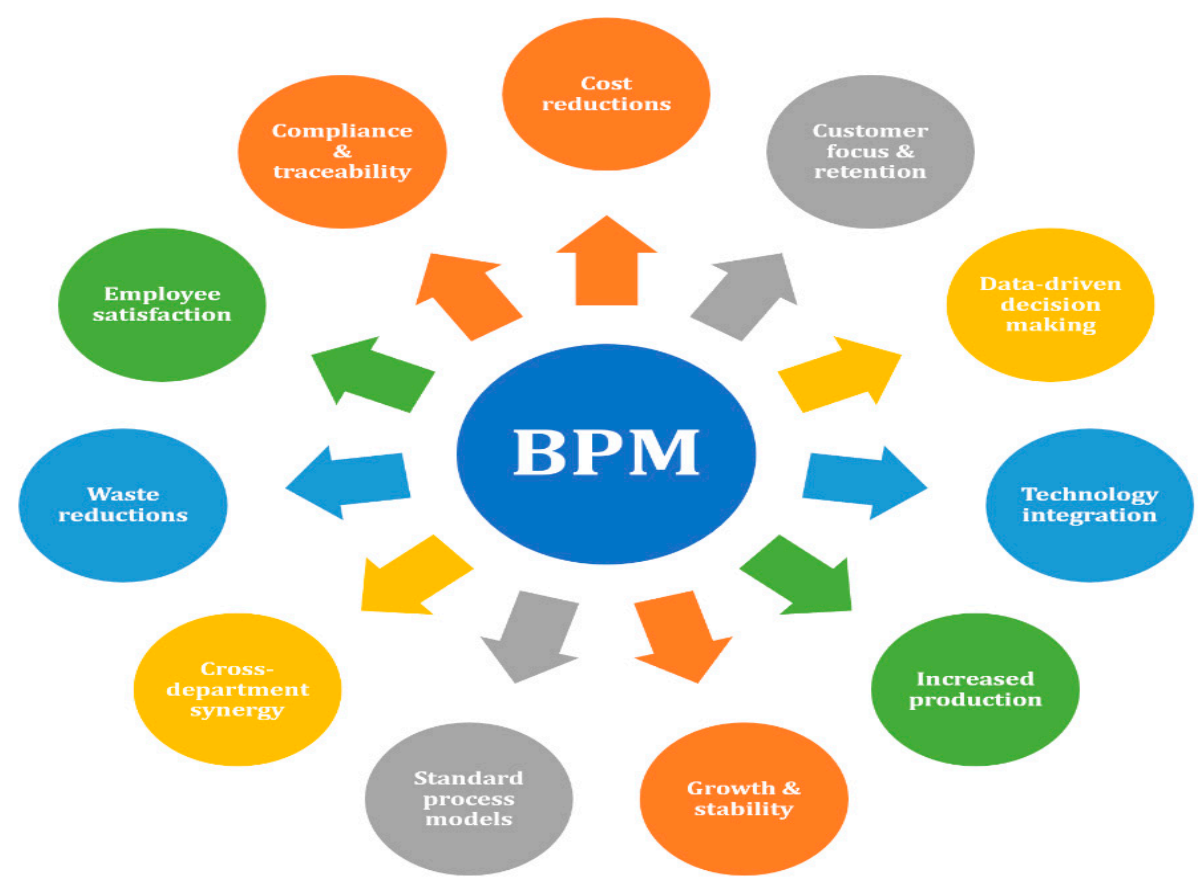

Figure 3. Benefits offered by business process management.

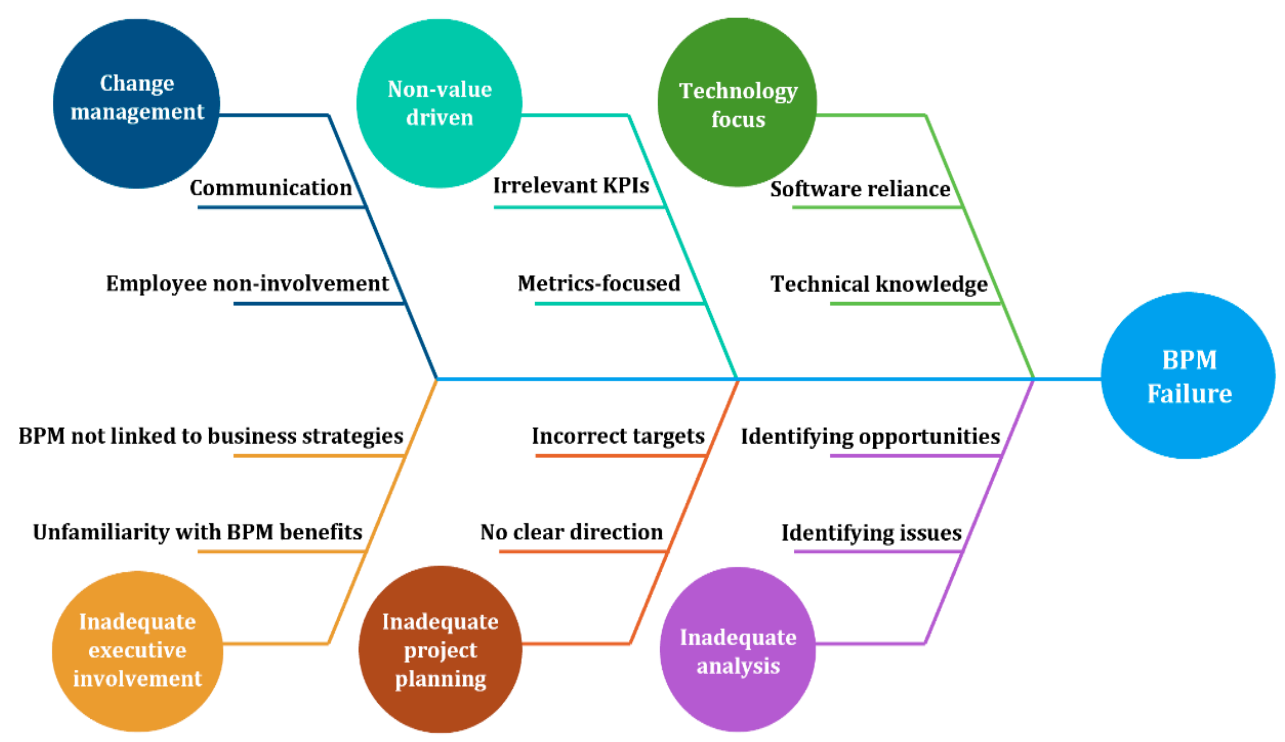

Figure 4. Cause and effect diagram for the failure of business process management (BPM) initiatives.

\section{Conceptualization of Integrated Business Process Management Framework}

It is evident from the literature that Industry 4.0 technologies require integration throughout an organization to capitalize on their benefits, and this means strategizing to streamline their impact on all the business processes. Therefore, the central question of this study is: how can BPM be used to support digital transformation through Industry 4.0? Considering that BPM can leverage an organization's performance and provide a structured method to incorporate changes, this study adopted a narrative literature review strategy [152], to propose a conceptual integrated business process management (IBPM) framework rooted in the traditional BPM method to support digital transformation. The main characteristic of a narrative review format is its broad view of the research and diversity of sources [153]. The narrative review of the literature can be summarized in a conceptual framework by highlighting the interaction and focal points $[154,155]$. An unstructured search for 
articles in leading databases (e.g., Science Direct, Emerald Insight, Springer Link, Taylor \& Francis Online) was conducted. The framework was built by considering the aspects that are often overlooked in Industry 4.0 transition, and their impact on the digital transformation of an organization, such as skills gap analysis, risk management, contingency planning, change management, and cost-benefit analysis. These factors have been identified by the author through his work on a European funded project, Growing into Industry 4.0 (focused on identifying the barriers related to the uptake of Industry 4.0 [18]), while working with several manufacturing companies. Using 'industry 4.0', coupled with the under-investigated factors shown in Table 1 as keywords, the most relevant papers were selected that highlight their interrelationship. The literature formed the basis for IBPM and the framework with its associated phases is shown in Figure 5. This work is not focused on developing a systematic literature review, but presenting a conceptual framework supported by literature that highlights key areas often overlooked due to the sheer volume of technological changes presented by Industry 4.0. The proposed IBPM framework can be used by manufacturing organizations as an implementation method, to support their journey towards digital transformation based on Industry 4.0 technologies. The different phases of the IBPM framework with their associated challenges are discussed in the subsequent sections.

Table 1. Literature used to support the integrated business process management framework.

\begin{tabular}{ll}
\hline \multicolumn{1}{c}{ Main Topics } & \multicolumn{1}{c}{ References } \\
\hline BPM & {$[147-151,156-164]$} \\
\hline Skills gap & {$[165-172]$} \\
\hline Risk management & {$[173-179]$} \\
\hline Change management & {$[180-188]$} \\
\hline Cost-benefit analysis & {$[2,22,189-194]$} \\
\hline Lean/Six Sigma/Lean Six Sigma & {$[22-25,143,195-199]$} \\
\hline
\end{tabular}

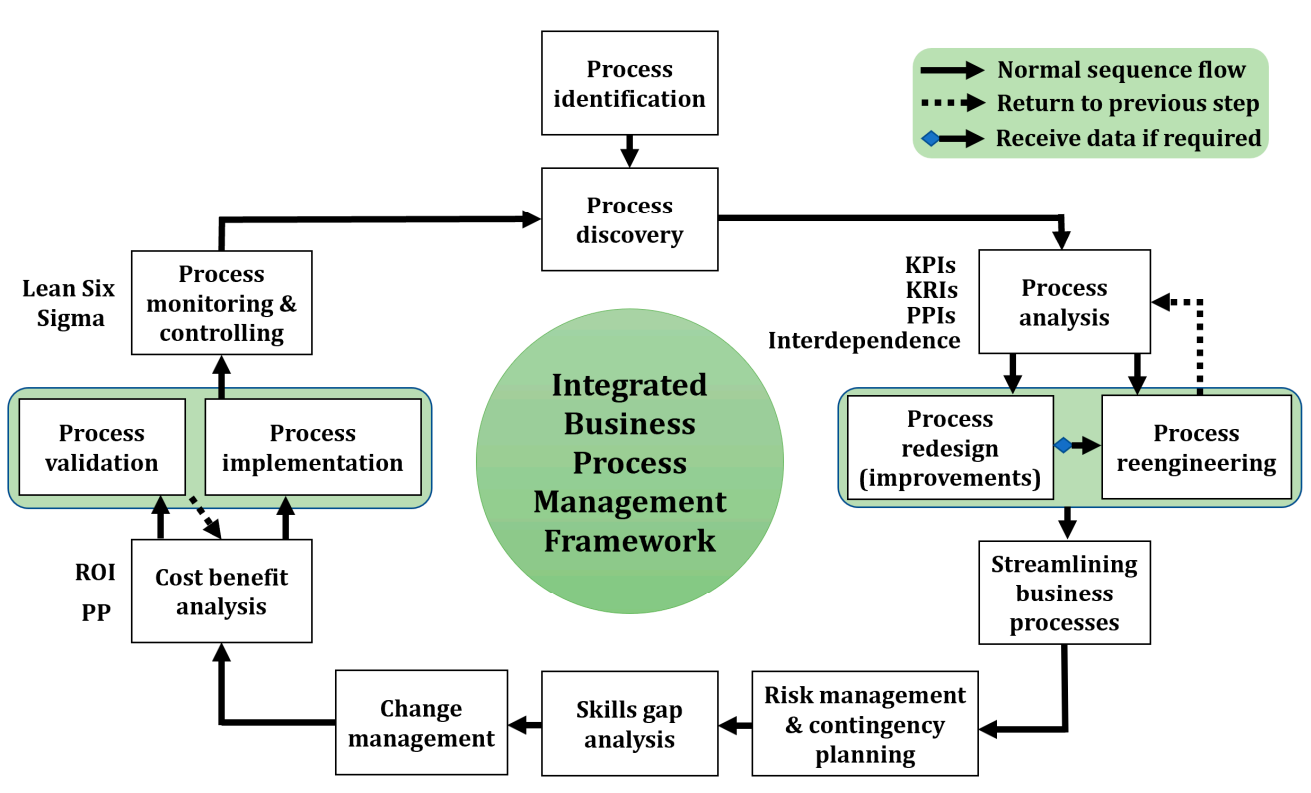

Figure 5. Integrated business process management framework.

\subsection{Phase 1: Process Identification}

In the very first phase of the IBPM framework, a business problem is posed by the IBPM team, comprised of senior management members, process owners, process participants, process analysts, and system engineers from each department of the organization. The reason for having such a diverse 
team is to ensure that a consistent approach could be employed to identify processes relevant to the problem being addressed. The majority of the time, BPM failure stems from the inability of the implementation team to connect the factors from different departments that influence the smooth running of operations. An appropriate IBPM team would help in delimiting the pertinent factors and would be able to relate them to each other more effectively. It is crucial to outline the processes that require improvement or reengineering from the start and develop a quantifiable measure for their success. One of the core elements of BPM (discussed in Section 4) is strategic alignment, hence aligning the IBPM initiative with the core strategies of the organization is important to ensure appropriate support from senior management and less resistance from the workforce. Figure 6 presents an overview of common organizational strategies, defined in three levels [200], and strategies related to the employment of Industry 4.0 technologies. At this stage, it is essential to align the IBPM initiative with the organizational strategies, but also to be mindful of Industry 4.0 focused strategies that can form the basis (depending on organizational priorities), either in the later stages of the IBPM cycle or during the second iteration of the IBPM method. In addition to IBPM team formation, the strategic alignment of the BPM initiative, and approaches of measuring success, it is also crucial to define the expectations and requirements of internal (employees) and external (customers) stakeholders. This phase can be supported by undertaking a SWOT (strength-weakness-opportunity-threat) analysis that can help in identifying internal strengths and weaknesses of the organization, as well as its external opportunities and threats [201]. There is also a need to identify functional and non-functional business requirements [202,203], to ensure that the efforts of the IBPM team are aimed in the right direction. Proper planning is the key in the first phase of the IBPM and should include the development of organizational charts (diagram showing the organizational structure and the relationships, as well as roles and reporting hierarchy of the people, involved [204]), stakeholder maps (layout showing the responsibilities of the people involved, their connection to each other, and who can influence the project [205]), context diagram (a tool for confirming the overall scope of the business function and the system integration requirements for process analysis [206]), and business use case diagrams (diagrams that can establish the context to confirm the functional scope of each business process within an organization [207]).

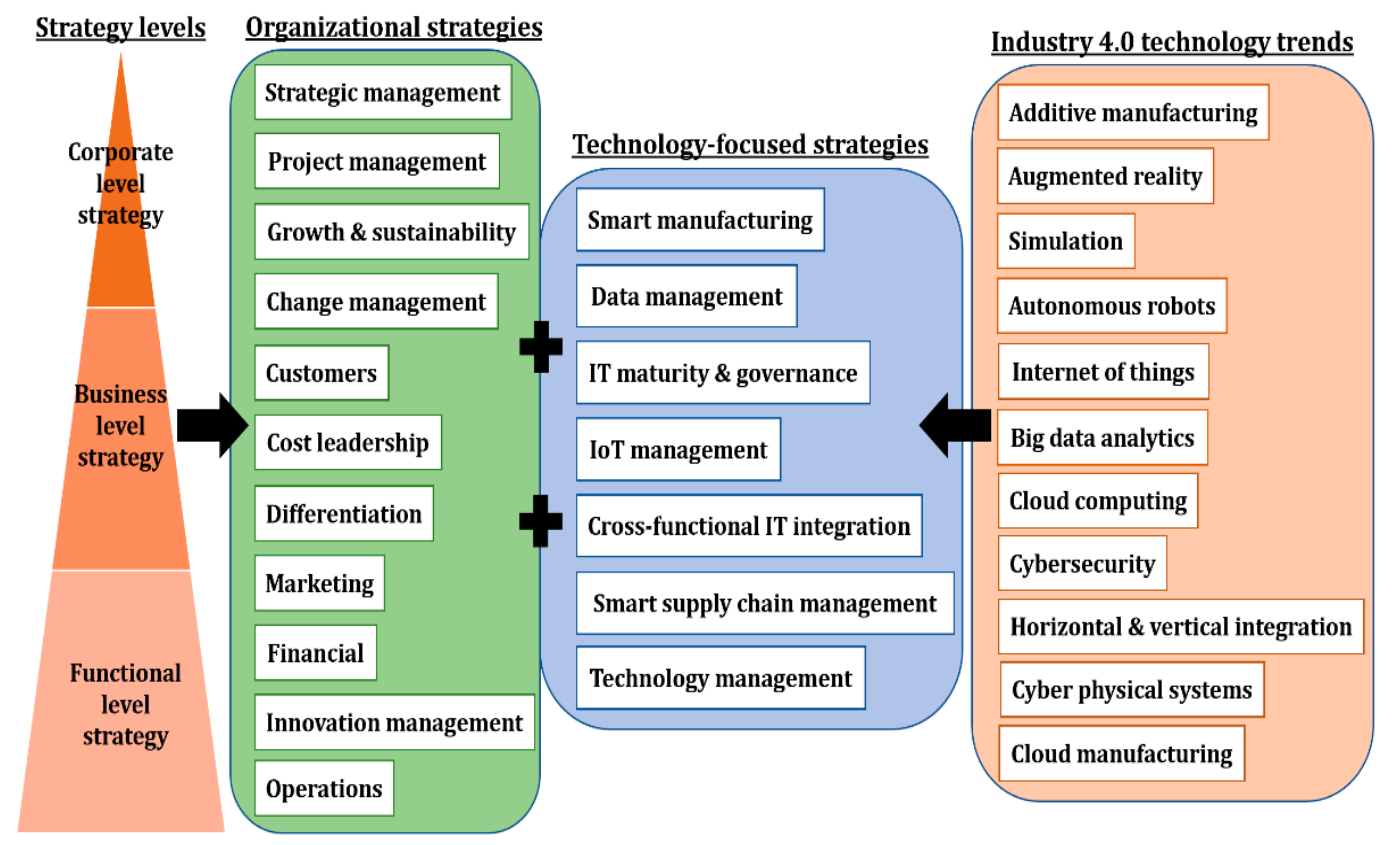

Figure 6. Strategic alignment for the BPM method. 


\subsection{Phase 2: Process Discovery}

The second phase involves the identification of the business process to be improved or reengineered. It involves characterizing and establishing the boundary and interfaces of the different business processes with each other and understanding their connection. For example, the business process to be improved/reengineered could be the main process, such as manufacturing, or a supporting process such as accounting (Section 4). A simple flow chart showing the connections between the main and supporting processes is shown in Figure 7. It is crucial to develop a visual representation of the identified process with a proper and realistic breakdown of sub-processes. At this stage, it would be tempting to develop a layout that shows what the process should be, but it must be drawn as 'it-is' (or 'as-is') to ensure that the shortcomings could be captured and appropriate actions could be taken. There are different ways the flow of activities for a specific business process could be recorded. It could be done by creating simple flow charts, either manually or by the use of simple software tools such as LucidChart, Microsoft Visio, and Creately [208]. These software packages work on business process modelling notation (BPMN), which is a standard method to model the steps of a planned business process from end to end [209]. A critical aspect of the 'as-is' process flow chart is the accuracy of the information, connections, sequence flows, and decision points. Value stream mapping is also a useful tool that displays the steps in a specific business process and shows the flow of both materials and information as they progress through the process to the end-user [210]. The purpose is to form an 'as-is' process model that provides a common understanding and communication among the stakeholders. This will help the IBPM team to assess the process flow and its shortcomings, to develop innovative solutions.

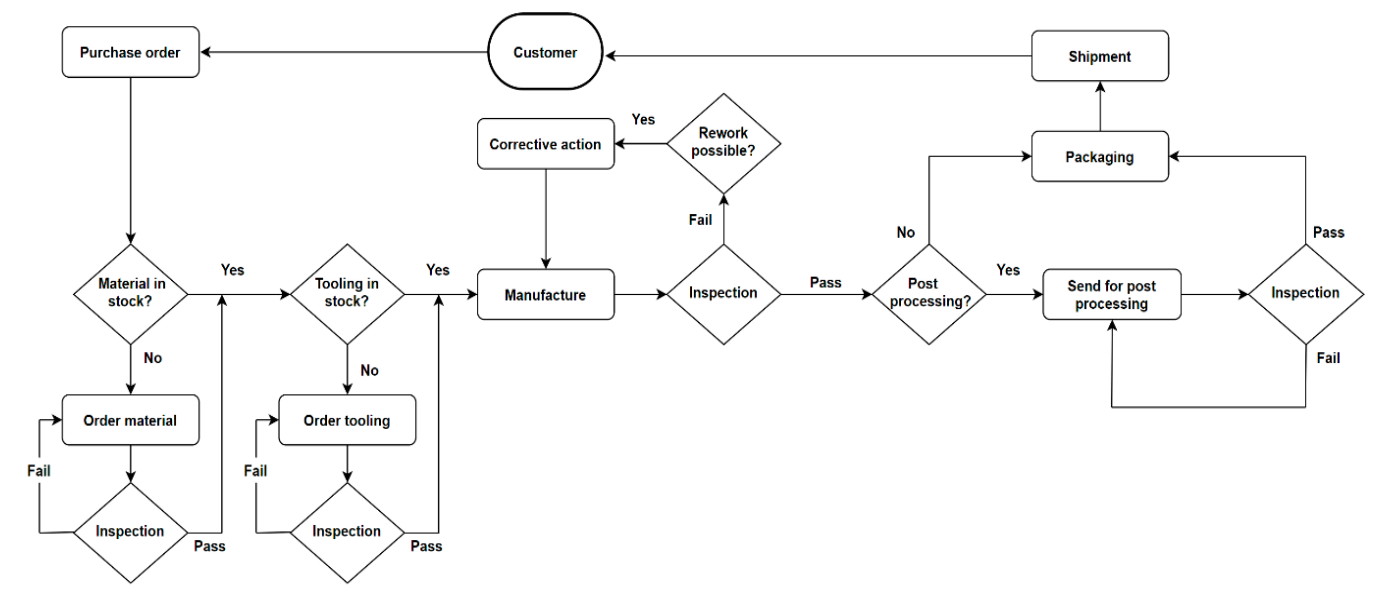

Figure 7. Sample flow chart of operations.

\subsection{Phase 3: Process Analysis}

Understanding a business process is the key to its effective management. The primary aim of this step is to review and analyze the identified 'as-is' process to be improved. The idea is to define key performance indicators (KPIs), metrics, key risk indicators (KRIs), and process performance indicators (PPIs). These are important to understand the requirements of the process and to recommend effective modifications. KPIs and metrics go hand in hand and should reflect strategic drivers, and should be consistent with the vision and goals of the organization. A KPI is a measure of performance and success [211], whereas a metric is a quantifiable number within a KPI that helps track performance and progress [212]. KPIs should be identified effectively to ensure that beneficial decisions could be made. As KPI is a measure of how well something is being done, KRI is an indicator of the possibility of future adverse impact [213]. Business risks need to be meticulously identified and when metrics provide an early warning, regarding an increased risk exposure in a certain area of operations, they become KRIs. They can provide an overview of the risk profile for a specific business process [214]. 
KRIs measure the potential risk related to a specific action that the organization is considering, as well as the risk inherent in the company's day-to-day operations [215]. PPIs are defined as quantifiable metrics that allow the evaluation of the efficiency and effectiveness of business processes. They can be measured directly by data that is generated within the process flow and are aimed at the process of controlling and continuous optimization. They can also be considered as process-related KPIs [216]. All the indicators should satisfy the SMART (specific-measurable-assignable-realistic-time related) criteria, and should be related to a specific outcome that can be supported through a set of metrics. Every indicator can be considered as a metric, but not every metric is an indicator. Some examples of KPIs, KRIs, and PPIs for a manufacturing process are shown in Table 2.

Table 2. Examples of key performance indicators (KPIs), key risk indicators (KRIs), and process performance indicators (PPIs).

\begin{tabular}{|c|c|c|}
\hline Category & Description & Definition \\
\hline \multirow{4}{*}{ KPIs [217] } & Overall equipment effectiveness & $\begin{array}{l}\text { Measures equipment efficiency across three areas i.e., availability, performance, } \\
\text { and quality. }\end{array}$ \\
\hline & Manufacturing cycle efficiency & Measures value-added time as a percentage of throughput time. \\
\hline & First pass yield & $\begin{array}{l}\text { Percentage of products manufactured correctly and to specs the first time } \\
\text { through the process. }\end{array}$ \\
\hline & Capacity utilization & Measures how much a line, plant, or factory uses its total production capacity. \\
\hline \multirow{4}{*}{ KRIs $[214,218]$} & Mean time between failure & $\begin{array}{l}\text { The average amount of time elapsed between machine failures, measured from } \\
\text { the moment the machine initially fails, until the time that the next failure occurs. }\end{array}$ \\
\hline & Mean time to repair & $\begin{array}{l}\text { The average amount of time required to repair a system to full functionality } \\
\text { following a failure measured from the time that the failure occurs until when } \\
\text { the repair is completed. }\end{array}$ \\
\hline & $\begin{array}{l}\text { Downtime percentage due to } \\
\text { scheduled activities }\end{array}$ & $\begin{array}{l}\text { The total amount of downtime that has been set aside for planned system } \\
\text { maintenance activities (as opposed to unplanned downtime) as a percentage of } \\
\text { total downtime (planned and unplanned) during the measurement period. }\end{array}$ \\
\hline & $\begin{array}{l}\text { Percentage of missed scheduled } \\
\text { maintenance activities }\end{array}$ & $\begin{array}{l}\text { The number of scheduled maintenance activities related to machines that did } \\
\text { not take place on or before their scheduled date as a percentage of all } \\
\text { maintenance activities scheduled to occur over the same period. }\end{array}$ \\
\hline \multirow{4}{*}{ PPIs [219-221] } & Process effectiveness & $\begin{array}{l}\text { Relationship between the actual process results and the expected process } \\
\text { results. It is a combination of time, quality, and cost. }\end{array}$ \\
\hline & Process efficiency & $\begin{array}{l}\text { Relationship between the results achieved by a process and the resources } \\
\text { consumed in that process. }\end{array}$ \\
\hline & Process compliance & $\begin{array}{l}\text { Refers to internal (percentage of non-conforming products) and external } \\
\text { (compliance with government regulations) compliance. }\end{array}$ \\
\hline & Throughput time & $\begin{array}{c}\text { Represents the amount of time it takes to run a given process, from raw } \\
\text { material to the finished product. }\end{array}$ \\
\hline
\end{tabular}

Business activities do not run independently, as there are significant associations and dependencies among them. Process dependency analysis enables one to describe interdependence between processes, based on information, materials, or execution. Therefore, it is critical to identify and analyze different types of interdependence within a specific business process. It is to be noted that like the KPIs, KRIs, and PPIs, interdependencies will differ for different business processes. An understanding of task interdependence will help the IBPM team grasp how different business processes, departments, and team members rely on the performance of one another. Even if they work independently, there are various consequences (positive or negative) that should be considered to create the most effective processes. Generally, there are three types of process interdependence i.e., pooled, sequential, and reciprocal [222]. Pooled interdependence refers to the team members sharing the loose or unstructured responsibility for reaching the goal while working in independent teams. Sequential interdependence happens when one department or team must accomplish something before another team can do their job and it is the most common type of interdependence in manufacturing processes with assembly lines. Reciprocal interdependence is bi-directional, where teams or departments rely on one another, making everyone highly responsible for accomplishing goals and tasks [223]. Identifying interdependence is a critical factor and should be done consistently. 
A data-driven approach should be employed, where the interdependence of every single machine (for a manufacturing process) or function is analyzed, quantified, and corrective action is taken for enhanced performance [224].

Process analysis should also involve qualitative and quantitative approaches. In the former, a useful technique is value-added analysis (VAA) that helps in identifying problems within a process and distinguish the steps into business value-added (BVA), value-added (VA), or non-value-added (NVA) activities [225]. For quantitative analysis, process simulations using software packages are beneficial, as different scenarios could be visualized and studied without physical implementation. This phase will provide the IBPM team an indication whether the business process under analysis is aligned with organizational goals and objectives or not. Overall, the output of this phase is a structured collection of indicators, process issues, areas of improvement, and inconsistencies. These aspects should be prioritized by the IBPM team in terms of their impact, and in terms of the estimated effort required to address them, as the action points will form the basis for the next phase.

\subsection{Phase 4: Process Redesign or Reengineering}

The goal of this phase is to identify changes to the process that would help to address the issues identified in the previous phase. This could involve either redesigning (improving) the existing process or reengineering/designing a new process, to meet the performance objectives of the organization. Both options require alignment with the organizational strategies to ensure compliance with Phase 1. Simulation tools are extremely useful at this stage, as they can help in virtually analyzing different workflows for improvements and designing new systems to investigate their performance. There are several packages capable of simulating manufacturing-process-flow based on various modeling paradigms, including process-centric, systems dynamics, Petri net, Monte Carlo simulations, and agent-based. These packages include, but are not limited to WITNESS, AnyLogic, FlexSim, Simio, and Simul8 Professional. They can provide animated and interactive models to replicate the operation of an existing or proposed production facility. They can help solve common manufacturing challenges, that include assessing the impact of investment, production planning, optimization, and scheduling, facility designing, manufacturing capability planning, bottleneck analysis, resource allocation, and last but not least, plan Industry 4.0 approaches [48-50]. The output of this phase is typically a 'to-be' process model, incorporating promising changes for better results. The IBPM team should develop alternative or new concept designs based on Phase 3 ('as-is' process) analysis. The choice of redesign or reengineered design requires an in-depth analysis of the challenges and opportunities offered by the two options. Ideas related to new process designs should be developed and discussed, but the IBPM team should consider the knock-on effect throughout the organization.

The new alternatives should consider the full breadth of the project scope, to ensure that a truly digital transformation is achieved by the organization. Not all ideas will meet the requirements, therefore, a prioritized list of design features should be developed, and the best options based on thorough analysis (either by simulation or mathematical calculations) should be discussed. The process experts and the R\&D team should be involved in this step. It is necessary to brainstorm and facilitate the design process using FMEA (failure mode and effects analysis) or a cause-and-effect diagram. Being innovative and creative will help the organization to remain competitive. However, it is also crucial to use established tools for reducing the number of possible designs. The team can use a problem-solving, analysis, and forecasting tool called TRIZ (theory of inventive problem-solving), that focuses on universal principles of creativity to formulate innovative solutions that might have been generated to solve a different problem in a different sphere of scientific investigation [226]. After generating some concepts ideas, an evaluation should take place to identify the optimal design. This can be done by using the Pugh Matrix. It is an easy-to-use qualitative technique that can help in ranking the multidimensional options generated to identify the optimal option [227]. The purpose of the Pugh Matrix is to provide the IBPM team with a holistic view of stakeholder (internal and external) requirements against different alternatives in the form of a matrix, instead of listing the positives and 
negatives of each option. This helps in qualitatively identifying the optimal option. These approaches can be used for both redesign and reengineering options.

Considering that there are two options to contend, it is crucial to understand the implications of both. For the redesign, there is an implied acceptance of the current processes. Therefore, the main focus of the IBPM team would be to use the results from Phase 3 and incrementally devise solutions for those issues, taking one issue at a time. These issues could stem from performance indicators, risks, or interdependence studies. For example, if the process to be redesigned is a manufacturing process, as shown in Figure 8, comprising sensors, tools, actuators, controllers, and networked systems [228], then the incremental improvements would involve strategically adding Industry 4.0 enabling technologies, to ensure optimal performance. The addition of BDA will help in predictive modelling to support decision making that can be utilized for ingesting and integrating copious amounts of data from the production floor [229], leading to better production or maintenance planning. However, these incremental changes should be guided by Industry 4.0 design principles (Section 3), as they will support the IBPM team in identifying and implementing Industry 4.0 scenarios for enhanced performance.

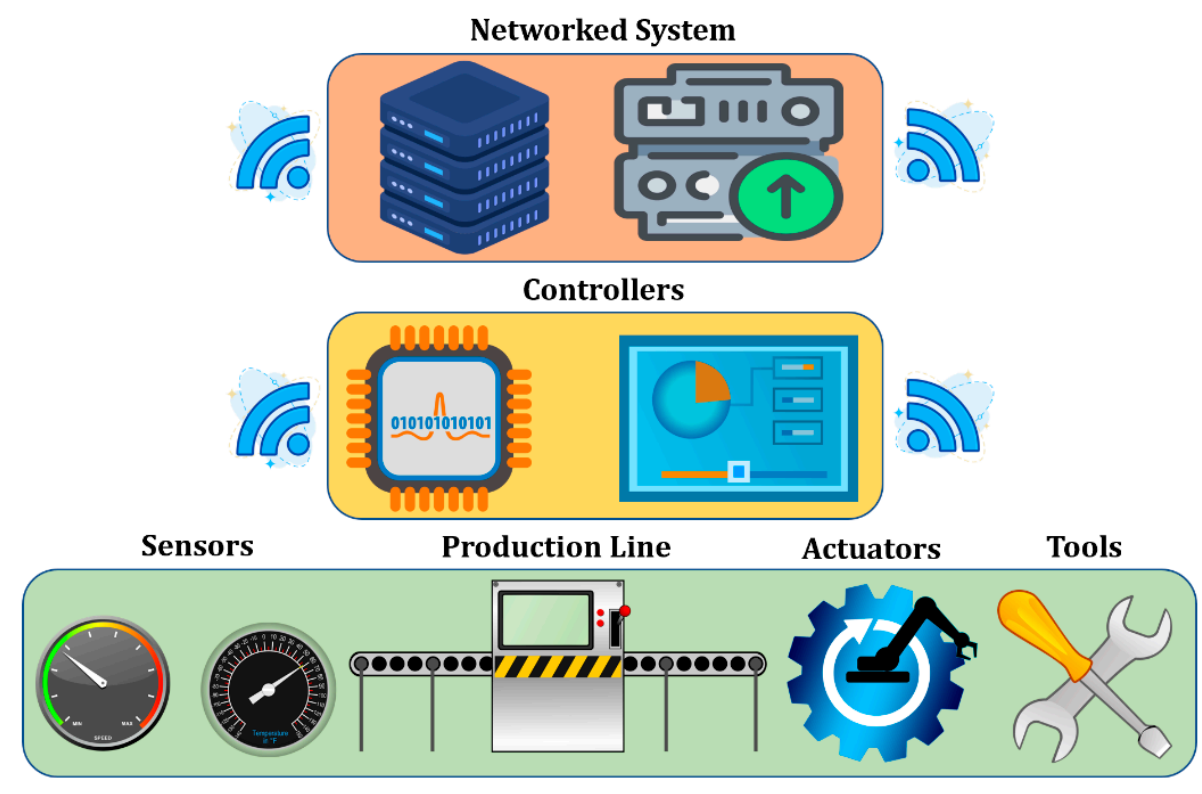

Figure 8. Manufacturing process in today's factories.

On the other hand, designing a new manufacturing process (reengineering) to incorporate Industry 4.0 enabling technologies will be a massive undertaking, but the effort will be justified with the rewards. This step can also be informed by the interdependence analysis and the VAA done for the redesigned process, but the focus should be on designing the workflow by incorporating Industry 4.0 technologies. It is highly recommended to include industry experts to aid in the design phase, as incorporating the full breadth of Industry 4.0 is still a work in progress. Most industrial installations today making use of IoT concepts typically embed sensors in manufacturing equipment or tag products with RFID tags. The data coming from these devices undergo comparatively little analysis. This is only the beginning step. The real value in these systems comes from using an information system to analyze the IoT data, then using the information to make informed decisions. This is one of the reasons why the reengineered design should be developed with the help of experts and should incorporate the capabilities of the associated digital technologies. Using the example of a manufacturing process, the new design will lead to the development of CPS (Section 2.10) in manufacturing called cyber manufacturing (Section 2.11). The 5C architecture of the CPS is shown in Figure 9. The move from today's manufacturing process (Figure 8) to cyber manufacturing (Figure 9) will entail a strict adherence to Industry 4.0 design principles (Section 3), to realize the full benefits of digitalization, as shown in Figure 10. There is 
a need to analyze the newly designed process for KPIs, KRIs, PPIs, and interdependencies, to ensure that it can still meet the organizational goals. The newly designed process should go back to the 'Process Analysis' phase and should form its basis as the 'as-is' process to be moved to the next phase of redesign. This approach will help in the establishment of a singular 'to-be' process at the end of Phase 4, rather than multiple options with different considerations (as shown in Figure 5). The IBPM team should not be overwhelmed by the sheer volume and velocity of Industry 4.0 technologies, and only focus on incorporating the ones that fit the strategic needs of the organization, or provide a solution to the business problem posed in Phase 1. Digital transformation initiatives fail for many reasons, e.g., a business trying to do too much without a proper focus or goal, emphasizing on simply introducing new technologies without assessing their role within the business, compartmentalizing digital initiatives from the rest of the business, or a large-scale implementation of digitalization without a realistic view of return on investment $[197,230]$. The IBPM team should try to avoid these by proper planning and continuous communication.

In either case (process redesign or reengineering), the IBPM team should make a decision based on the long-term vision of the organization and the available resources. There is a need to be mindful of the alternatives on offer for both options, but the key would be to realistically define a 'to-be' process from the 'as-is' process in-line with the strategic requirements of the organization, to either move gradually or radically towards digital transformation. The requirements and activities needed for process redesign and reengineering will be different. Therefore, it is crucial not to overlook the VAA performed in Phase 3. The IBPM team should focus on reviewing each step of the VAA, develop simulation models for the 'to-be' process based on the improvements by getting rid of the NVA activities, and finalize an optimal workflow for the next phase.

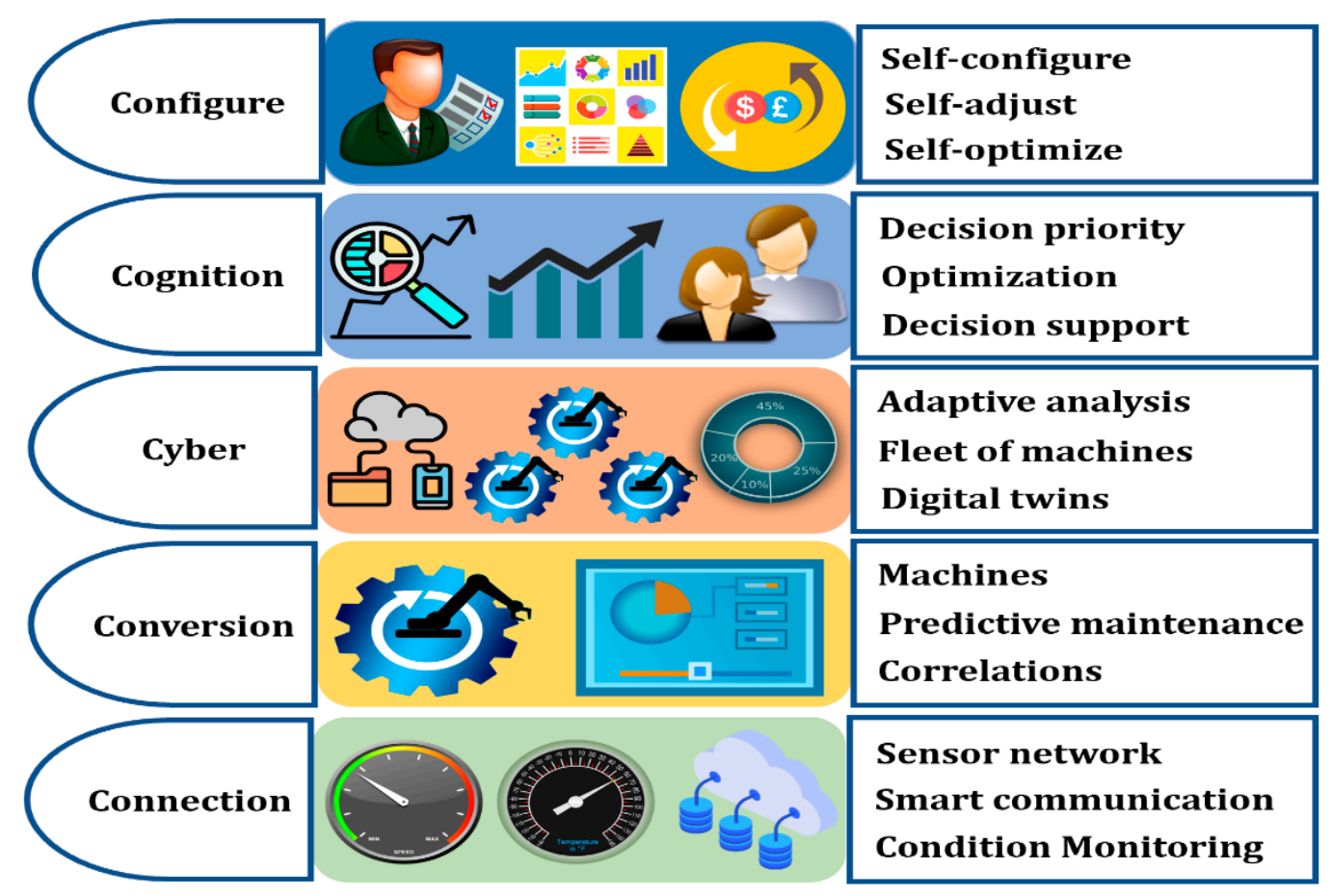

Figure 9. Techniques and levels of the $5 \mathrm{C}$ (connection, conversion, cyber, cognition, and configuration) architecture for cyber-physical systems (CPS). 


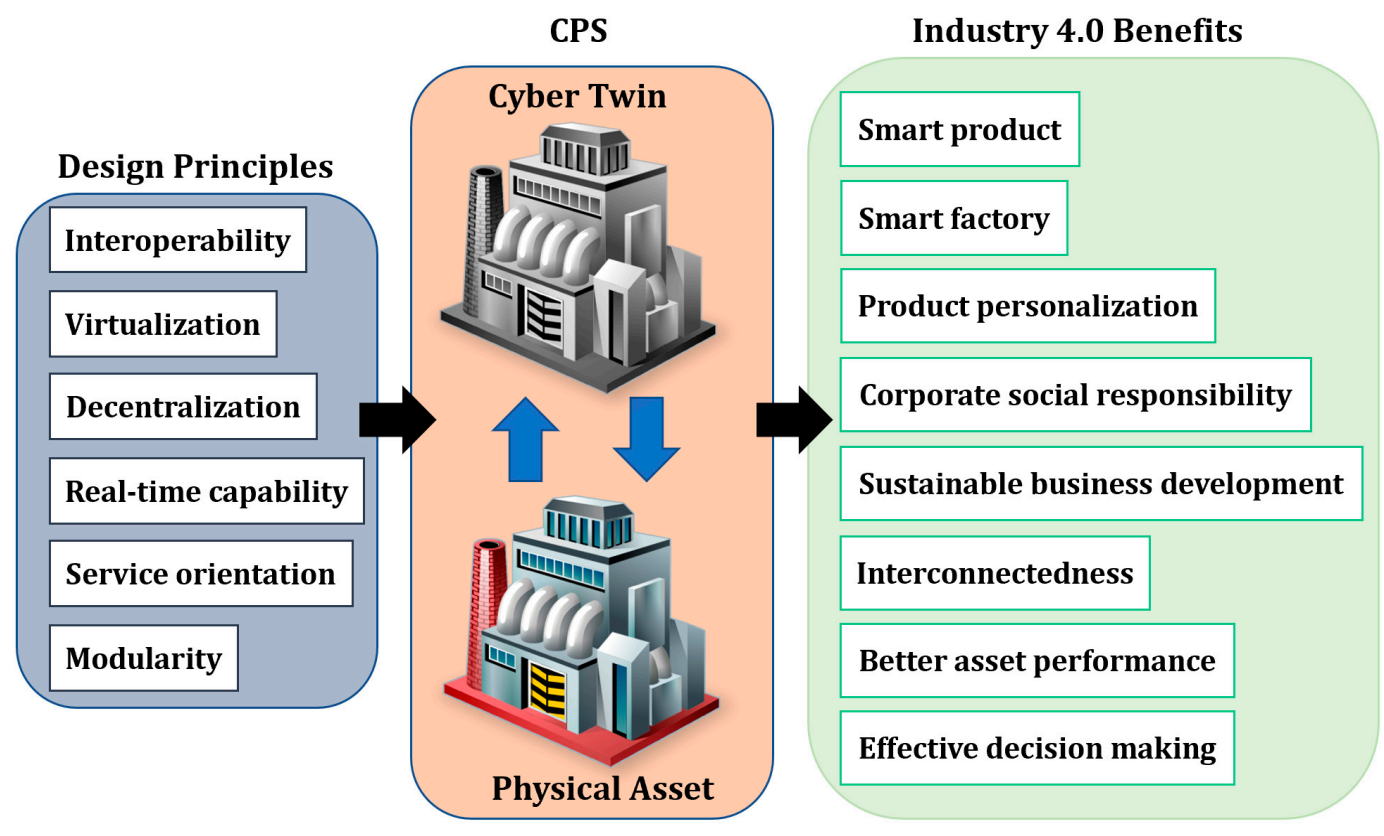

Figure 10. Benefits of adherence to Industry 4.0 design principles.

\subsection{Phase 5: Streamlining Business Processes}

As described in Phase 4, the 'to-be' process could result in process redesign (improvements) or a reengineered (new) design, with both options affecting the output from a single business process. Therefore, it is vital to streamline other business processes, to ensure that they can still work cohesively without causing disruption. For both options (i.e., redesign and reengineering), there could be changes in interdependencies between business processes (or departments), as a result of the 'to-be' process. The IBPM team needs to consider these changes and plan accordingly. Since the output of Phase 4 is a single 'to-be' process, regardless of whether it was a redesigned process model or a reengineered one, it should be streamlined with the associated business processes, to ensure a smooth flow of operations throughout the organization. Considering the example of manufacturing (Figure 11) as the process of attention, enhancing the manufacturing capacity will automatically increase sales, as more products will be made and sold. This will put a strain on the sales department to cope with the increase. Similarly, the inventory levels will also go up and the requirement for raw material will increase. The cash flow in and out of the organization will increase drastically. Not all organizations can cope with a sudden increase like this, and could be adversely affected due to a lack of agility and flexibility in their business processes. There need to be provisions put in place by the IBPM team to accommodate these changes of the 'to-be' process on the entire organization. The team should focus on analyzing the 'to-be' process, examine its outcomes from simulation models, and acquiring feedback from the team members and other staff to ensure that different scenarios and their impact is captured. This is where an open, cross-department, collaborative effort is encouraged to identify, analyze, and minimize the disruption to associated business processes. The IBPM team can also make use of interdependence studies among departments, to develop a holistic understanding of the dependent, interdependent, and independent tasks/activities, to aid the streamlining process. 


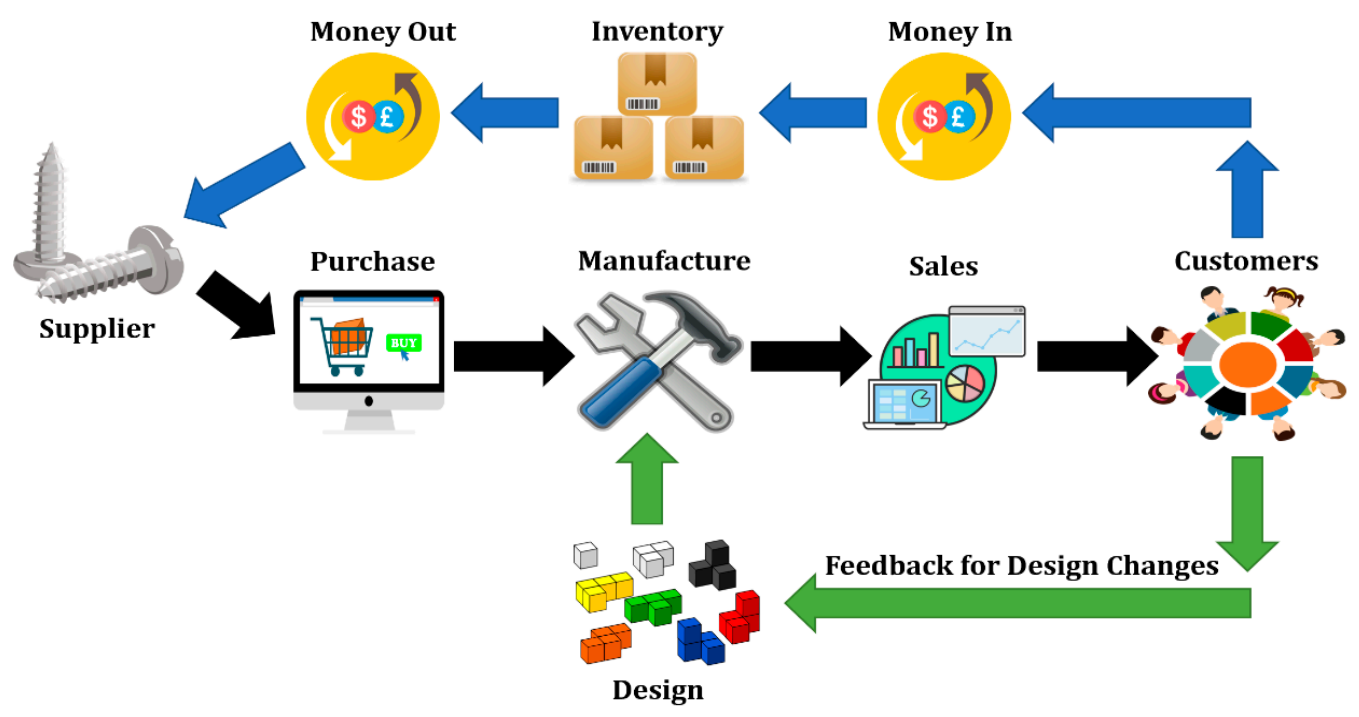

Figure 11. Relationship among different business processes.

\subsection{Phase 6: Risk Management and Contingency Planning}

Even though KRIs have been identified in Phase 3 and then reviewed based on the 'to-be' process, there is a need to incorporate risk management and contingency planning as a precursor to the next phases. Industry 4.0 builds complex, dynamic, and real-time connections between humans and systems for enhanced performance. These activities generate large data volumes in real-time, which causes new requirements of the infrastructure, management, and technologies. This could be viewed as more reasons to worry and more things that can go wrong than ever before [173-177]. The IBPM team should incorporate methods of avoiding, mitigating, transferring, and accepting risks. Risk intelligence is needed to collate information, to identify, assess, and treat risks [178,179,231]. Risks can be identified through brainstorming (group activity for the generation of a large number of ideas), premortem (imagining failure and listing the probable reasons), or counterfactual thinking (evaluating choices that were not made). A risk analysis can be done through developing a risk register, that includes evaluating risk probability and its impact. It is common practice for any new project to develop a risk register that quantifies the risk in terms of probability and impact followed by mitigation plans. The IBPM team should make use of this approach and record the probability and impact of their activities towards digital transformation. A sample risk assessment is shown in Figure 12 for Industry 4.0 implementation. The IBPM team should employ systems thinking approach that allows envisioning broad end-to-end impacts. For example, a cascading failure starts small, but becomes large with time and spreads across a system as a chain reaction of interconnected parts. Industry 4.0 is all about interconnectedness, therefore, the IBPM team must consider such failure modes as well [232]. Risk management includes steps before a risk occurs, whereas contingency planning focuses on steps to be taken if, or when, a risk occurs [233]. Both are crucial to maintaining and mitigating risks to the business. One major aspect of mitigating risks is knowing what to do when a risk occurs. This means that contingency planning can be considered as a component of risk management. Since the organization is moving in an unfamiliar direction with Industry 4.0, it is necessary to develop contingency plans for the identified and common risks (e.g., natural disaster or data losses) and communicate them to the employees. 


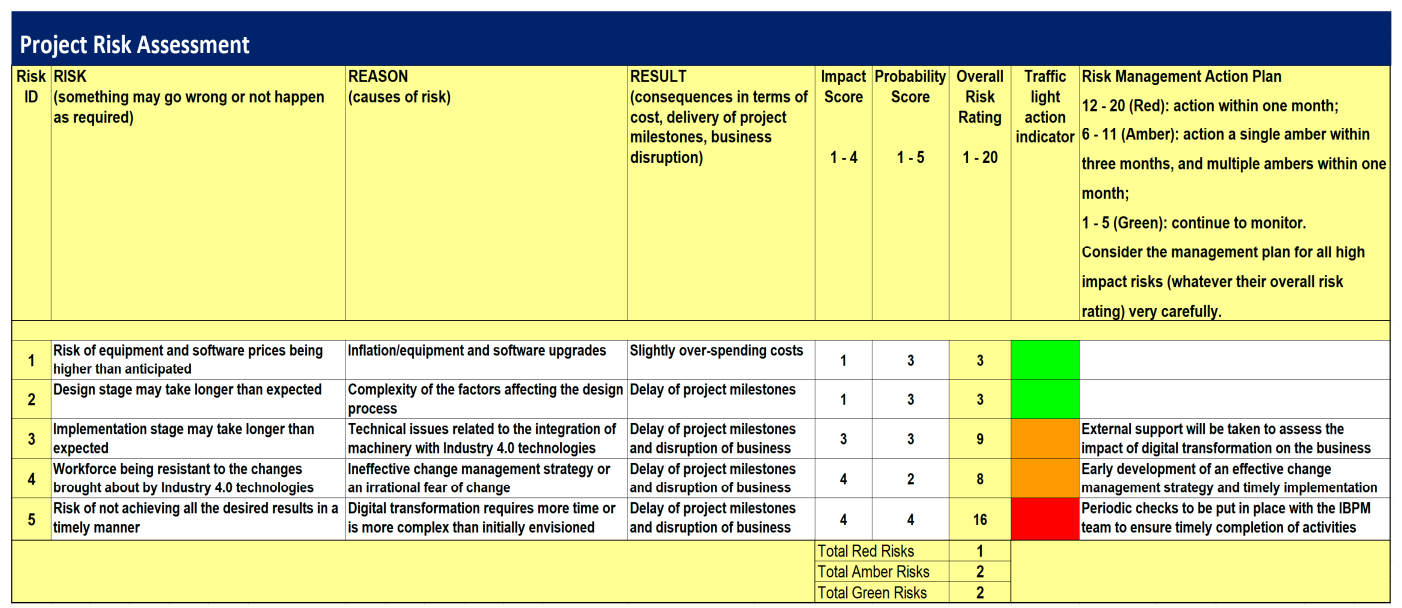

Figure 12. Sample risk assessment.

\subsection{Phase 7: Skills Gap Analysis}

There are many uncertainties around Industry 4.0, ranging from the lack of a proper definition to how it should be implemented, and whether organizations are ready for such a change [234,235]. There have also been initiatives to deal with such uncertainties and one such initiative is called Work 4.0. This is an umbrella term that encompasses and discusses the challenges of changing work due to Industry 4.0 enabling technologies and the possibility of widespread digitalization [236]. One of the key challenges highlighted in the framework of Work 4.0 is Industry 4.0 and human-machine interaction [237]. This raises serious concerns about job losses, the erosion of skills, and work intensification, to meet the technological demands of the business. Considering this challenge, it is imperative to invest in boosting skills and improving individual prospects for advancement at an early stage. The target for such a skills upgrade should not only be low-skilled workers or the people directly responsible for technical work, but the organization as a whole, to ensure that everyone can participate in value creation. This is why the IBPM team should conduct a skills gap analysis, to analyze the existing skills of the workforce and the required skills, based on the strategic goals of the organization. In the beginning, the focus should be on the workforce directly involved with the business process being investigated, and then should spread out evenly throughout the organization. It is widely reported that organizations are struggling to ensure that their workforce possesses the skills required to thrive in the Industry 4.0 landscape $[238,239]$. It is not a matter of simply attracting the right talent with the required skills and retaining them, but also developing the skillset of the existing workforce. This needs a cultural shift where the organization takes initiative to upskill its workforce, rather than expecting people to develop themselves in their own time. Due to the uncertainty around Industry 4.0 skills, even senior management finds it hard to gauge the required skills [240]. This is because technologies such as BDA, robotics, and IoT are rapidly changing the workplace. Considering manufacturing as an example, the IBPM team should analyze aspects such as what the activities are, what skills the existing workforce possess, what tools assist them in their work, what happens in a normal working day, and compare them to what these would look like in a digital world. Based on this analysis, the IBPM team should utilize established frameworks to gauge workforce skills and plan workshops for their development. Worker 4.0 is such a framework that highlights the hybrid competencies (a mixture of adaptive, technological, and technical skills) that the future workforce should possess [165]. The skills are highlighted in Figure 13 to show the variety of competencies needed to succeed in the digital age. In addition to the Worker 4.0 concept, there is also the concept of Operator 4.0, that represents the 'operator of the future', a smart and skilled operator who performs 'work aided by machines', if and as needed [166-172]. This framework is more focused on the technological side of Industry 4.0. For example, an analytical operator who uses BDA [241], an augmented operator who uses AR [167], and a smarter operator who uses AI-based technologies [242]. These are also informed by Industry 4.0 
design principles; therefore, they should be the primary focus of the IBPM team during this phase. For example, an analytical operator can support system integration, an augmented operator can support modularity, and a smarter operator can support decentralization. To support the workforce in developing such hybrid skills and competencies, the IBPM team should plan for workshops built on theories of motivation, communication, and futures studies related to the anticipation of future change to make the workforce future literate [243]. Future literacy is important, as it can help the workforce in identifying their developmental needs to be effective in the digital world. These workshops need to be planned, managed, and delivered with clear objectives, to ensure a successful outcome for both the workforce and the organization.

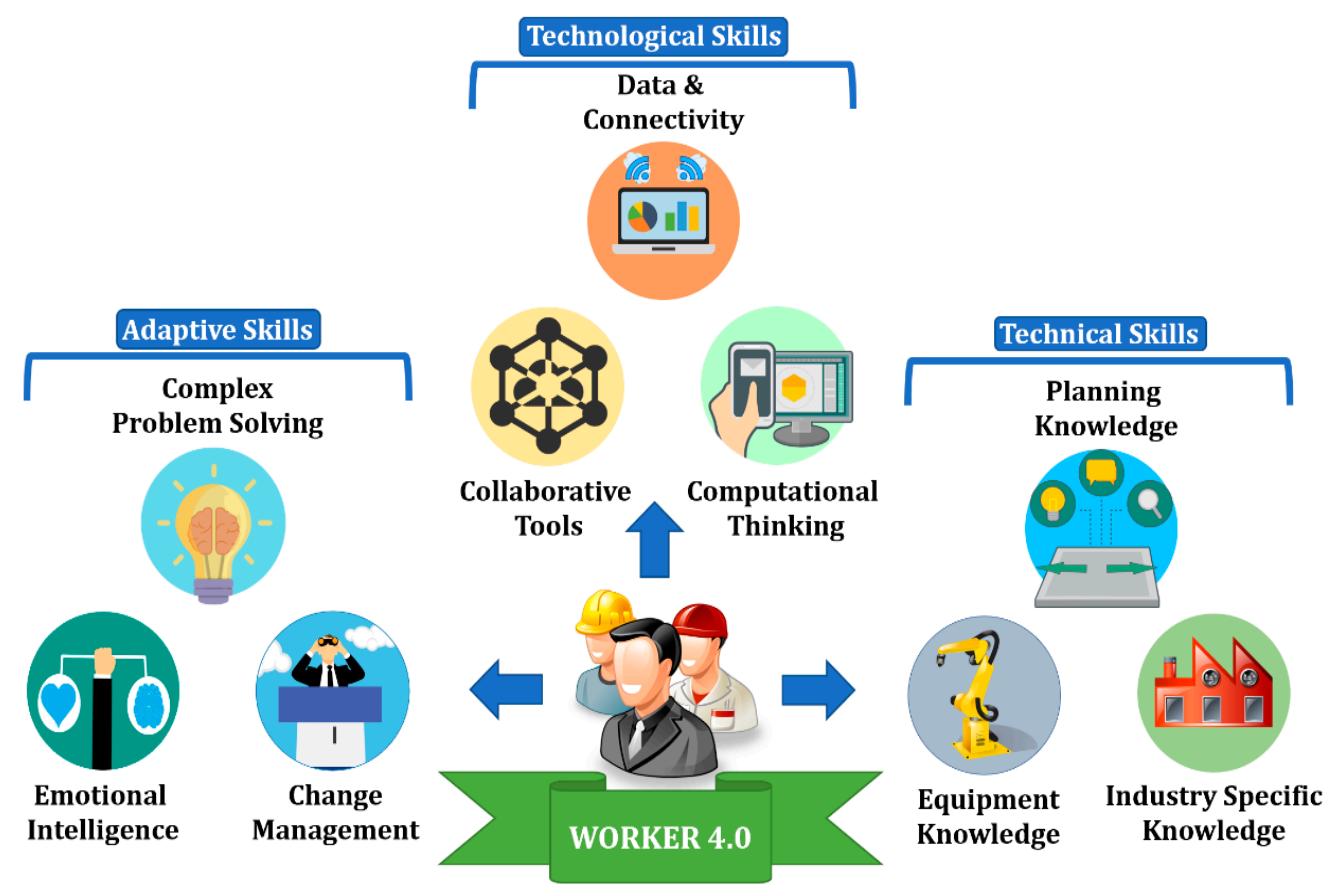

Figure 13. Worker of the future's hybrid competencies.

\subsection{Phase 8: Change Management}

This is perhaps the most crucial phase, as mismanagement here would be catastrophic to the business. Change management is a collective term for all approaches to prepare, support, and help individuals, teams, and organizations in making organizational changes [244]. Moving towards digital transformation is a major change, and it will naturally create resistance and restlessness throughout the organization, with people being afraid of losing their jobs, not getting promoted promptly, or refusing to change their traditional ways of working. The IBPM team will need to manage the move towards Industry 4.0 very carefully, by focusing on the workforce. People are complicated and this is never more evident than when dealing with a change [245]. Changes can be unexpected or intentional. The former would be the case when making changes due to the pandemic of COVID-19 [246], whereas the latter would be something like implementing Industry 4.0 knowingly and willingly. In case of this intentional change, the role of the IBPM team is to ensure that they develop a formal approach for managing change by collating the data and opinions of key stakeholders at an early stage, and stay proactive in updating that data pool and the relevant stakeholders [180,181]. Change management needs to include every part of the organization to ensure that there is ample support available during uncertain times, as this would be crucial in retaining skilled individuals [182,183]. The IBPM team should present a formal case to highlight the need for change and its subsequent impact in an open setting and articulate how it fits with the strategic goals of the organization [184]. This could be extremely challenging, and the team could face severe backlash if their approach is not open and 
honest $[185,186]$. This is where the IBPM team needs to be proactive and assess the cultural landscape beforehand, to understand how change has been managed in the past. This can serve as a baseline for designing essential change elements and can also help in establishing a contingency plan (discussed in Phase 6). The IBPM team needs to effectively manage this change through a continual reassessment of its impact and the organization's willingness, as well as the ability to adapt to the next wave of transformation [247-249].

There are different well-established models for understanding, planning, implementing, and communicating change, e.g., Lewin's change management model, McKinsey 7S model, Kotter's change management theory, and ADKAR model. The IBPM team should choose the one that they understand and are confident in implementing. For example, Lewin's change management model can be used, that comprises three steps of unfreeze, change, and refreeze. 'Unfreeze' entails preparing the organization to accept that change is necessary, which involves breaking down the existing status quo before building up a new way of operations. 'Change' state requires time and effective communication to ensure that new ways are being implemented, with proper justifications and the workforce being aware of how this change meets the organizational objectives. When the changes are taking shape and people have embraced the new ways of working, the organization is ready to 'refreeze' by documenting and standardizing the new protocols $[250,251]$. Humans are the major challenge in managing change, because of their natural tendency to resist it, as it could mean moving away from the norm, or doing more than what they are used to doing on a normal working day. The IBPM team can manage this through the Prosci ADKAR model. ADKAR is an acronym for awareness, desire, knowledge, ability, and reinforcement [252]. According to the model, the process of becoming ready for change is sequential, starting from the current level of each individual, and none of the five steps could be avoided, skipped, or reordered [253]. This can work well, as the first three could be gauged by the skills gap analysis in Phase 7, whereas the last two can be instilled through the workshops in Phase 7 planned by the IBPM team. This shows a complete synergy of activities within different phases, where one phase complements the other in the framework of integrated business process management.

There is also an underlying issue that should be addressed by the IBPM team. Change management is often viewed as a project with a definitive start, middle, and endpoints. However, in the digital age, with the accelerated developments and technological advancements, there would be no end to change management, as it would be an on-going effort. The IBPM team can lay the foundation for this by fostering a mindset that can accept and appreciate the fact that change in this day and age is characterized by ongoing and overlapping transitions at a rapid rate. Business leaders should learn to manage continuous states and operate with a dynamic change-readiness approach [254,255]. Through this change management regime, the IBPM team can sow the seeds for adoption management. There needs to be a change in the internal mindset, to focus on prioritizing a state of continuous evolution and adjustment on the go [256]. Adoption management is about creating lasting change through culture, education, and technology that can lead to continuous change [257]. This would be a challenging task, and therefore, the IBPM team should design a change management strategy with clear indicators of adoption management, to gradually change the mindset of the workforce, and senior management to instill the idea that there is no end to change and it needs to be managed continuously in a dynamic manner and in-line with the organizational goals.

\subsection{Phase 9: Cost-Benefit Analysis}

One of the main barriers to Industry 4.0 adoption is the inability to realistically estimate the value it would bring to an organization [22,190-192]. Converting benefits to monetary value is considered to be extremely challenging, because most managers themselves are unaware of what Industry 4.0 technologies can do, and in what areas it can benefit their organization [193,258]. There are several tools available that can guide one through the different steps to calculate return on investment (ROI), payback period (PP), and benefits to cost ratio (BCR). It is highly dependent on how in-depth analysis the organization intends to perform, keeping in mind that the more thorough the analysis is, the more 
resources would need to be deployed to collate data. In this phase, the IBPM team needs to consider every single benefit that can result by employing Industry 4.0 enabling technologies, convert the benefits into monetary value, and judge against the associated costs. Typically, envisioning benefits is the most difficult aspect of such estimations, as people find it easier to estimate costs [259]. The IBPM team should consider taking advantage of the external Industry 4.0 experts hired in Phase 4 , to ensure that they can identify appropriate benefits and then use process owners to quantify those benefits and discuss the costs of implementation.

ROI requires a comprehensive evaluation of the collected data, therefore, the IBPM team should consider using an established and well-structured framework for their analysis. One such approach is called Phillips ROI Methodology ${ }^{\mathrm{TM}}$, comprising 10 steps divided into four phases [260]. The first phase is evaluation planning, consisting of two steps, i.e., developing project objectives and evaluation plans. The second phase is called data collection and comprises two steps, i.e., collecting data before/during and after project implementation. The third phase is data analysis and is the most challenging one with five steps, i.e., isolating project effects, capturing project costs, converting data to monetary value, calculations for ROI, PP, or BCR, and finally, identifying intangible benefits. The last phase is the reporting phase that deals with developing and disseminating the results of the implementation to stakeholders (internal and external). This is quite a comprehensive approach and takes sound planning, data collation activities, and analysis methodologies. The IBPM team needs to conduct several interviews, surveys, record the opinions of the workforce on different matters, and most importantly, put resources in place to collate data [261]. It is to be noted that certain criteria in quantifying the benefits are subjective to the situation and nature of the business, hence, the people involved in the calculation process must acknowledge the complexity and situational variables to arrive at an optimal result [262]. The IBPM team should also ensure that there are no exaggerations in benefits calculations or associated costs [263].

The IBPM team needs to consider every single aspect of a specific Industry 4.0 technology separately first, and then in combination with others, to develop a holistic understanding of the benefits. Phillips ROI Methodology ${ }^{\mathrm{TM}}$ is an example to show that a structured method should be followed, to ensure that a realistic cost-benefit estimation can be achieved. There are several methods available in the literature that take into consideration other factors, such as phased investments with over one-year PP [264], and calculating net present value or internal rate of return [265]. However, converting data to monetary value is common to all methods, regardless of the final inference. If we consider an example of a manufacturing process where different parts require manual assembly by operators and plan to employ augmented reality to expedite their performance, then a cost-benefit analysis can be undertaken. Firstly, there is extensive literature on increased worker performance using AR protocols [52-58] that the IBPM team should consider. Secondly, this example also works well with the 'augmented operator' in the Operator 4.0 framework discussed in Phase 7, that shows compliance with established Industry 4.0 protocols, that should make the identification and subsequent analysis easier. The approach should be to analyze what is being changed, what effect it will have, and what will be its significance. The difficulty would not only be in identifying benefits, but realistically quantifying them as well. Table 3 shows an example breakdown of some benefits and costs associated with employing AR, to develop the concept of an augmented operator on the shop floor. The IBPM team should conduct similar extensive cost-benefit analysis in this phase, based on the 'to-be' process developed in Phase 4 through simulation models. This will form the basis for the next phase, where the simulations will be validated through pilot runs before moving to full-scale implementation. 
Table 3. Identification of project costs.

\begin{tabular}{|c|c|c|}
\hline \# & Benefits & Monetary Value \\
\hline 1 & Improvements in profit due to the reduction of assembly time & $\mathrm{X} 1$ \\
\hline 2 & Error reductions & $\mathrm{X} 2$ \\
\hline 3 & Time savings & $\mathrm{X} 3$ \\
\hline 4 & Increased performance & $\mathrm{X} 4$ \\
\hline 5 & Faster learning for existing and new workers & $\mathrm{X} 5$ \\
\hline 6 & More products assembled during a normal working shift & $\mathrm{X} 6$ \\
\hline \multirow[t]{3}{*}{7} & $\begin{array}{l}\text { Intangible benefits (higher employee satisfaction/engagement, } \\
\text { reduction of stress in employees, teamwork, job satisfaction) }\end{array}$ & - \\
\hline & Total & $\mathbf{X X}$ \\
\hline & Costs & Monetary Value \\
\hline 1 & Special software and hardware & Y1 \\
\hline 2 & $\begin{array}{l}\text { Storage capacity for data and hardware in specific digital and } \\
\text { physical spaces, respectively }\end{array}$ & Y2 \\
\hline \multirow[t]{6}{*}{3} & Training of individuals & $\mathrm{Y} 3$ \\
\hline & Total & $Y Y$ \\
\hline & Calculations & Results \\
\hline & $\mathrm{ROI}=\frac{X X-Y Y}{Y Y} * 100$ & $\mathrm{ZZ} \%$ \\
\hline & $\mathrm{PP}=\frac{Y Y}{X X} * 12$ & ZZ months \\
\hline & $\mathrm{BCR}=\frac{Y Y}{X X}$ & ZZ:1 \\
\hline
\end{tabular}

\subsection{Phase 10: Process Validation and Implementation}

This phase focuses on validating the simulation models developed in Phase 4 to an acceptable level of difference. Depending upon the level of detail and the complexities of the 'to-be' process, several scaled pilot runs could be conducted, to ensure the seamless integration of all the defined strategies from Phase 1. The IBPM team should plan and conduct a pilot run, as it can help in minimising failure risks, providing more effective control, confirming or disproving established interdependencies in Phase 3, identifying additional improvements in either the solution or implementation launch itself, and improving future projections of benefits of full-scale implementation $[266,267]$. The team should ensure that the pilot is reversible and does not significantly disrupt the normal business processes. It should involve proper planning, clear goals, assign responsibilities, budgeting, data collation methods, and measurement protocols for comparisons with the required targets. Communication is the key to ensure that everyone is on-board and plays their role appropriately. The pilot 'to-be' system should be exposed to a variety of inputs and process conditions. The IBPM team should systematically analyze the differences between the predicted performance and the actual performance after the pilot run, to identify improvement opportunities [268].

After validating the simulation models through pilot runs, the results should be communicated to stakeholders and their feedback should be recorded [269]. This should form the basis for a full-scale implementation plan. The plan should be adjusted based on the results, analyses, and opportunities from the pilot run and for the difference in the scale of the rollout. The IBPM team should identify factors favoring/opposing the full-scale implementation, and recognize implications, as well as risks, from failing to address the obstacles. There is also a need to conduct another cost-benefit analysis, to ensure that a full-scale implementation is a viable option for the organization. It could be the case that the organization is happy to continue running a scaled model parallel to their existing business processes and intends to integrate the 'to-be' process gradually, over a longer period than previously 
planned. This could be due to a lack of resources, a huge skills gap, resistance from the workforce, or lack of flexibility and agility in the existing business processes.

The successful validation of the 'to-be' business process model should lead to full-scale implementation. If the organization is happy with the results, then the IBPM team should plan a full-scale pilot, by following the same protocols used in the scaled pilot run. The full-scale pilot of the 'to-be' process would be a permanent deployment that delivers fully on the organizational goals. Change management will be a key factor here, and that is why it was addressed in Phase 8 , with a focus on adoption management. The IBPM team should look to include more senior management staff at this point, and some members from the original IBPM team should be trained to become 'digital champions', to continue the transformation by creating a sense of ownership among the workforce $[22,270]$. After the successful implementation of the 'to-be' business process, data should be collated, and the matrices should be compared with Phase 1, to ensure that the project yielded the required results for the organization. The operating procedures should be documented and standardized. A future management plan should be developed by the IBPM team, to continuously monitor the new process, address the training needs of the workforce, and identify opportunities for improvements [271].

\subsection{Phase 11: Process Monitoring and Controlling}

Once the 'to-be' business process is running, relevant data should be collated by the IBPM team to perform a post-implementation review of the new process for continuous improvements. The data should be analyzed to determine the efficacy of the new process concerning its performance measures and objectives. Common issues in manufacturing systems such as bottlenecks, recurrent errors, or deviations should be identified, and corrective actions should be undertaken. The findings of the monitoring and evaluation should be shared within the organization to serve as feedback into the iterative IBPM improvement lifecycle. As time goes by, new issues may arise in the same or in other business processes that would require the IBPM cycle to be repeated again. The IBPM team should focus on three aspects in this phase i.e., the performance of the processes, process management, and of the organization as a whole. Process monitoring and controlling is an on-going activity and should be employed to aid in continuous improvement of business processes. There are several approaches capable of providing the intended benefits. Lean six sigma approaches would be a good fit. In this case, DMAIC (define, measure, analyze, improve, control) would work well and is a well-established and commonly used BPM tool [272-274].

\section{Conclusions}

The adoption of Industry 4.0 is no longer a choice. It has become a necessity for businesses to succeed in the market. This has created serious doubts and concerns over the right time and approach for digital transformation. The lack of standardized implementation protocols is a major limiting factor. This paper has presented a conceptual framework termed as integrated business process management, that can help manufacturing organizations transition from traditional manufacturing to Industry 4.0. The framework has incorporated under-investigated factors to ensure that the organizations are minimizing their risk of failure. The use of the business process management method gives manufacturers a sense of familiarity, as they have been employing these principles for decades. Major reasons for the rejection of Industry 4.0 implementation methodologies by manufactures are fear of the unknown and resistance to change, whereas the use of business process management can mitigate them. The framework has presented a structured approach with clearly defined phases and associated challenges to ensure that it can reduce the uncertainty around Industry 4.0 implementation. The pandemic of COVID-19 has expedited the planning phase, with organizations moving swiftly towards Industry 4.0 implementation. In this context, the integrated business process management framework can prove beneficial and can serve as a good template to drive business-specific objectives forward. 
The proposed IBPM framework differs from the traditional BPM method in a couple of ways. Firstly, it incorporates factors that are often overlooked in Industry 4.0 implementation, e.g., skills gap analysis, risk management, contingency planning, change management, and cost-benefit analysis. It shows their significance and how they should be incorporated to ensure that a smooth transition is achieved. Secondly, it does not show over-reliance on technological tools for the implementation, but provides a more human-centric approach to analyze issues and develop rational solutions. BPM is an established method, and has been used for decades by manufactures to ensure that their business processes are efficient and effective. It is one of the most comprehensive and encompassing concepts available for businesses to generate a competitive advantage through cost reduction, process excellence, and continuous process improvement. That is why it was chosen as the basis of the IBPM approach to support digital transformation in the manufacturing sector. The IBPM framework provides effective governance (static and dynamic) to direct the digital transformation by considering the core elements of BPM, i.e., strategic alignment, governance, methods, information technology, people, and culture. It further involves intricate features (e.g., fiscal, risk/change management, hybrid competencies) that can help in developing an agile culture throughout the organization based on digital technologies. Digitalization, IoT, and big data analytics are just a few of the disruptions that require radically rethinking the way business processes operate. The pace of change is increasing with business processes continuously evolving to meet customer requirements. Under these circumstances, it is critical for BPM to evolve as well, to accommodate such changes. IBPM should be considered as an evolved version of BPM, as a response to the rapid technological changes that have significantly transformed the manufacturing sector. The phases of IBPM have been discussed in Section 5 and they show complete synergy of activities, where one phase complements the other to support digital transformation in the manufacturing sector. The associated challenges that manufacturing organizations may face while transitioning into Industry 4.0-enabled digital enterprises have also been highlighted, and appropriate solutions based on literature have been presented to mitigate them.

It is to be noted that there are no standardized protocols for Industry 4.0 implementation, and any implementation strategy, such as IBPM proposed in this work, should be adapted based on the nature of the business, its complexities, and interdependencies to ensure a favorable outcome. On the other hand, ineffective management of such a framework could lead to significant losses in revenue, customers, and intellectual property. Solutions to different challenges have been presented in this work, that should be used to manage the digital transformation effectively and to develop business-specific solutions. The integrated business process management framework presented in this paper can support the manufacturing organizations in their pursuit of digital transformation. It is deeply rooted in BPM that can minimize resistance towards its adoption and can give the confidence to expedite the move towards Industry 4.0. The next stage of the work would be the implementation of the IBPM framework in a manufacturing organization for digital transformation.

Funding: This research did not receive any external funding.

Conflicts of Interest: There is only one author; hence, there is no conflict of interest.

\section{References}

1. Khan, S. Leadership in the Digital Age: A Study on the Effects of Digitalisation on Top Management Leadership. Master's Thesis, Stockholm University, Stockholm, Sweden, 2016.

2. Ghobakhloo, M. The future of manufacturing industry: A strategic roadmap toward Industry 4.0. J. Manuf. Technol. Manag. 2018, 29, 910-936. [CrossRef]

3. Hermann, M.; Pentek, T.; Otto, B. Design principles for industrie 4.0 scenarios. In Proceedings of the 2016 49th Hawaii International Conference on System Sciences (HICSS), Koloa, HI, USA, 5-8 January 2016; IEEE: Koloa, HI, USA, 2016; pp. 3928-3937.

4. Sarı, T.; Güleş, H.K.; Yiğitol, B. Awareness and readiness of Industry 4.0: The case of Turkish manufacturing industry. Adv. Prod. Eng. Manag. 2020, 15, 57-68. 
5. Butt, J. Exploring the interrelationship between additive manufacturing and Industry 4.0. Designs 2020, 4, 13. [CrossRef]

6. Basl, J. Pilot study of readiness of Czech companies to implement the principles of Industry 4.0. Manag. Prod. Eng. Rev. 2017, 8, 3-8. [CrossRef]

7. Machado, C.G.; Winroth, M.; Carlsson, D.; Almström, P.; Centerholt, V.; Hallin, M. Industry 4.0 readiness in manufacturing companies: Challenges and enablers towards increased digitalization. Procedia CIRP 2019, 81, 1113-1118. [CrossRef]

8. Available online: https://slcontrols.com/benefits-of-industry-4-0/ (accessed on 20 May 2020).

9. Ardolino, M.; Rapaccini, M.; Saccani, N.; Gaiardelli, P.; Crespi, G.; Ruggeri, C. The role of digital technologies for the service transformation of industrial companies. Int. J. Prod. Res. 2018, 56, 2116-2132. [CrossRef]

10. Moeuf, A.; Pellerin, R.; Lamouri, S.; Tamayo-Giraldo, S.; Barbaray, R. The industrial management of SMEs in the era of Industry 4.0. Int. J. Prod. Res. 2018, 56, 1118-1136. [CrossRef]

11. Heavin, C.; Power, D.J. Challenges for digital transformation-towards a conceptual decision support guide for managers. J. Decis. Syst. 2018, 27 (Suppl. 1), 38-45. [CrossRef]

12. McKinsey \& Co. Digital Manufacturing: The Revolution will be Virtualized. 2015. Available online: https://www.mckinsey.com/business-functions/operations/our-insights/digital-manufacturing-therevolution-will-be-virtualized (accessed on 18 June 2020).

13. Ardito, L.; Petruzzelli, A.M.; Panniello, U.; Garavelli, A.C. Towards Industry 4.0: Mapping digital technologies for supply chain management-marketing integration. Bus. Process Manag. J. 2019, 25, 323-346. [CrossRef]

14. Frank, A.G.; Mendes, G.H.; Ayala, N.F.; Ghezzi, A. Servitization and Industry 4.0 convergence in the digital transformation of product firms: A business model innovation perspective. Technol. Forecast. Soc. Chang. 2019, 141, 341-351. [CrossRef]

15. Available online: https://ec.europa.eu/growth/tools-databases/dem/monitor/tags/industry-40 (accessed on 20 May 2020).

16. Available online: https://innovateuk.blog.gov.uk/2017/03/28/what-does-the-fourth-industrial-revolution-4irmean-for-uk-business/ (accessed on 20 May 2020).

17. Urciuoli, L.; Hintsa, J.; Ahokas, J. Drivers and barriers affecting usage of e-Customs-A global survey with customs administrations using multivariate analysis techniques. Gov. Inf. Q. 2013, 30, 473-485. [CrossRef]

18. Available online: https://northsearegion.eu/growin4/about-the-growin-40-project/ (accessed on 20 May 2020).

19. Müller, J.M.; Däschle, S. Business model innovation of industry 4.0 solution providers towards customer process innovation. Processes 2018, 6, 260. [CrossRef]

20. Zhu, Q.; Geng, Y. Drivers and barriers of extended supply chain practices for energy saving and emission reduction among Chinese manufacturers. J. Clean. Prod. 2013, 40, 6-12. [CrossRef]

21. Available online: https://www.industry.gov.au/funding-and-incentives/industry-40 (accessed on 20 May 2020).

22. Butt, J. A Strategic Roadmap for the Manufacturing Industry to Implement Industry 4.0. Design 2020, 4, 11. [CrossRef]

23. Sony, M. Industry 4.0 and lean management: A proposed integration model and research propositions. Prod. Manuf. Res. 2018, 6, 416-432. [CrossRef]

24. Apostolou, D.; Mentzas, G.; Stojanovic, L.; Thoenssen, B.; Lobo, T.P. A collaborative decision framework for managing changes in e-Government services. Gov. Inf. Quart. 2011, 28, 101-116. [CrossRef]

25. Zhang, C.; Liu, H.; Zheng, J. The model of BPM based on six sigma and its application on material delivery of discrete manufacturing enterprise. In Proceedings of the 2011 International Conference of Information Technology, Computer Engineering and Management Sciences, Nanjing, China, 24-25 September 2011; Volume 4, pp. 122-125.

26. Pessl, E.; Sorko, S.R.; Mayer, B. Roadmap Industry 4.0-implementation guideline for enterprises. Int. J. Sci. Technol. Soc. 2017, 5, 193-202. [CrossRef]

27. Colli, M.; Madsen, O.; Berger, U.; Møller, C.; Wæhrens, B.V.; Bockholt, M. Contextualizing the outcome of a maturity assessment for Industry 4.0. IFAC-Pap. 2018, 51, 1347-1352. [CrossRef]

28. Butt, J.; Shirvani, H. Additive, subtractive, and hybrid manufacturing processes. In Advances in Manufacturing and Processing of Materials and Structures; CRC Press: Boca Raton, FL, USA, 2018; pp. 187-218. 
29. Butt, J.; Shirvani, H. Experimental analysis of metal/plastic composites made by a new hybrid method. Addit. Manuf. 2018, 22, 216-222. [CrossRef]

30. Butt, J.; Onimowo, D.A.; Gohrabian, M.; Sharma, T.; Shirvani, H. A desktop 3D printer with dual extruders to produce customised electronic circuitry. Front. Mech. Eng. 2018, 13, 528-534. [CrossRef]

31. Butt, J.; Hewavidana, Y.; Mohaghegh, V.; Sadeghi-Esfahlani, S.; Shirvani, H. Hybrid Manufacturing and Experimental Testing of Glass Fiber Enhanced Thermoplastic Composites. J. Manuf. Mater. Process. 2019, 3, 96. [CrossRef]

32. Butt, J.; Bhaskar, R. Investigating the Effects of Annealing on the Mechanical Properties of FFF-Printed Thermoplastics. J. Manuf. Mater. Process. 2020, 4, 38. [CrossRef]

33. Butt, J.; Ghorabian, M.; Mohaghegh, V.; Shirvani, H. Finite Element Modeling and Mechanical Testing of Metal Composites Made by Composite Metal Foil Manufacturing. J. Manuf. Mater. Process. 2019, 3, 81. [CrossRef]

34. Leal, R.; Barreiros, F.M.; Alves, L.; Romeiro, F.; Vasco, J.C.; Santos, M.; Marto, C. Additive manufacturing tooling for the automotive industry. Int. J. Adv. Manuf. Technol. 2017, 92, 1671-1676. [CrossRef]

35. Yakout, M.; Cadamuro, A.; Elbestawi, M.A.; Veldhuis, S.C. The selection of process parameters in additive manufacturing for aerospace alloys. Int. J. Adv. Manuf. Technol. 2017, 92, 2081-2098. [CrossRef]

36. Youssef, A.; Hollister, S.J.; Dalton, P.D. Additive manufacturing of polymer melts for implantable medical devices and scaffolds. Biofabricatio 2017, 9, 012002. [CrossRef]

37. Strano, G.; Hao, L.; Everson, R.M.; Evans, K.E. A new approach to the design and optimisation of support structures in additive manufacturing. Int. J. Adv. Manuf. Technol. 2013, 66, 1247-1254. [CrossRef]

38. Langelaar, M. Topology optimization of 3D self-supporting structures for additive manufacturing. Addit. Manuf. 2016, 12, 60-70. [CrossRef]

39. Butt, J.; Ghorabian, M.; Ahmed, A.; Shirvani, H. Finite element modelling and validation of thermomechanical behaviour for layered aluminium parts made by composite metal foil manufacturing. J. Compos. Sci. 2018, 2, 68. [CrossRef]

40. Available online: https://3dprintingindustry.com/news/3d-printing-community-responds-to-covid-19-andcoronavirus-resources-169143/ (accessed on 21 April 2020).

41. Kok, Y.; Tan, X.P.; Wang, P.; Nai, M.L.S.; Loh, N.H.; Liu, E.; Tor, S.B. Anisotropy and heterogeneity of microstructure and mechanical properties in metal additive manufacturing: A critical review. Mater. Des. 2018, 139, 565-586. [CrossRef]

42. Tamura, H. Steady steps and giant leap toward practical mixed reality systems and applications. In Proceedings of the International Status Conference on Virtual and Augmented Reality, Leipzig, Germany, 5 November 2002; pp. 3-12.

43. Jung, T.; tom Dieck, M.C. Augmented Reality and Virtual Reality; Empowering Human, Place and Business; Springer International Publishing: Cham, Switzerland, 2018.

44. Tepper, O.M.; Rudy, H.L.; Lefkowitz, A.; Weimer, K.A.; Marks, S.M.; Stern, C.S.; Garfein, E.S. Mixed reality with HoloLens: Where virtual reality meets augmented reality in the operating room. Plast. Reconstr. Surg. 2017, 140, 1066-1070. [CrossRef] [PubMed]

45. Bonetti, F.; Warnaby, G.; Quinn, L. Augmented reality and virtual reality in physical and online retailing: A review, synthesis and research agenda. In Augmented Reality and Virtual Reality; Springer: Cham, Switzerland, 2018; pp. 119-132.

46. Chavan, S.R. Augmented reality vs. virtual reality: Differences and similarities. Int. J. Adv. Res. Comput. Eng. Technol. 2016, 5, 212611467.

47. Gracia, L.; Perez-Vidal, C.; Mronga, D.; de Paco, J.M.; Azorin, J.M.; de Gea, J. Robotic manipulation for the shoe-packaging process. Int. J. Adv. Manuf. Technol. 2017, 92, 1053-1067. [CrossRef]

48. Chi, H.L.; Kang, S.C.; Wang, X. Research trends and opportunities of augmented reality applications in architecture, engineering, and construction. Autom. Constr. 2013, 33, 116-122. [CrossRef]

49. Gervautz, M.; Schmalstieg, D. Anywhere interfaces using handheld augmented reality. Computer 2012, 45, 26-31. [CrossRef]

50. Zhou, F.; Duh, H.B.L.; Billinghurst, M. Trends in augmented reality tracking, interaction and display: A review of ten years of ISMAR. In Proceedings of the 2008 7th IEEE/ACM International Symposium on Mixed and Augmented Reality, Cambridge, UK, 15-18 September 2008; IEEE: Piscataway, NJ, USA, 2008; pp. 193-202. 
51. Piumsomboon, T.; Altimira, D.; Kim, H.; Clark, A.; Lee, G.; Billinghurst, M. September. Grasp-Shell vs. gesture-speech: A comparison of direct and indirect natural interaction techniques in augmented reality. In Proceedings of the 2014 IEEE International Symposium on Mixed and Augmented Reality (ISMAR), Munich, Germany, 10-12 September 2014; IEEE: Piscataway, NJ, USA, 2014; pp. 73-82.

52. Nee, A.Y.; Ong, S.K.; Chryssolouris, G.; Mourtzis, D. Augmented reality applications in design and manufacturing. CIRP Ann. 2012, 61, 657-679. [CrossRef]

53. Akçayır, M.; Akçayır, G. Advantages and challenges associated with augmented reality for education: A systematic review of the literature. Educ. Res. Rev. 2017, 20,1-11. [CrossRef]

54. Wake, N.; Bjurlin, M.A.; Rostami, P.; Chandarana, H.; Huang, W.C. Three dimensional printing and augmented reality: Enhanced precision for robotic assisted partial nephrectomy. Urology 2018, 116, 227-228. [CrossRef]

55. Lima, J.P.; Roberto, R.; Simões, F.; Almeida, M.; Figueiredo, L.; Teixeira, J.M.; Teichrieb, V. Markerless tracking system for augmented reality in the automotive industry. Expert Syst. Appl. 2017, 82, 100-114. [CrossRef]

56. Poushneh, A.; Vasquez-Parraga, A.Z. Discernible impact of augmented reality on retail customer's experience, satisfaction and willingness to buy. J. Retail. Consum. Serv. 2017, 34, 229-234. [CrossRef]

57. Chen, Y.P.; Ko, J.C. CryptoAR Wallet: A Blockchain Cryptocurrency Wallet Application that Uses Augmented Reality for On-chain User Data Display. In Proceedings of the 21st International Conference on Human-Computer Interaction with Mobile Devices and Services, Taipei, Taiwan, 1-4 October 2019; pp. 1-5.

58. Yung, R.; Khoo-Lattimore, C. New realities: A systematic literature review on virtual reality and augmented reality in tourism research. Curr. Issues Tour. 2019, 22, 2056-2081. [CrossRef]

59. Wörner, M.; Ertl, T.; Miksch, S.; Santucci, G. Visual analysis of advanced manufacturing simulations. In Proceedings of the EuroVa 2011: International Workshop on Visual Analytics, Bergen, Norway, 31 May 2011; pp. 29-32.

60. Acheson, C.; Mackle, D.; Murphy, A.; Butterfield, J.; Higgins, P.; Collins, R.; Tame, R. Using design of experiments to define factory simulations for manufacturing investment decisions. In Proceedings of the 34th International Manufacturing Conference, Sligo, Ireland, 30-31 August 2017.

61. Ruediger, P.; Hagen, H. Dealing with uncertainties in manufacturing process simulations. In Applied Mechanics and Materials; Trans Tech Publications Ltd.: Stafa-Zurich, Switzerland, 2017; Volume 869, pp. 226-233.

62. Esmaeilian, B.; Behdad, S.; Wang, B. The evolution and future of manufacturing: A review. J. Manuf. Syst. 2016, 39, 79-100. [CrossRef]

63. Demystifying Collaborative Industrial Robots. Available online: https://ifr.org/downloads/papers/IFR_ Demystifying_Collaborative_Robots.pdf (accessed on 3 April 2020).

64. Djuric, A.M.; Urbanic, R.J.; Rickli, J.L. A framework for collaborative robot (CoBot) integration in advanced manufacturing systems. SAE Int. J. Mater. Manuf. 2016, 9, 457-464. [CrossRef]

65. El Zaatari, S.; Marei, M.; Li, W.; Usman, Z. Cobot programming for collaborative industrial tasks: An overview. Robot. Auton. Syst. 2019, 116, 162-180. [CrossRef]

66. Michaelis, J.E.; Siebert-Evenstone, A.; Shaffer, D.W.; Mutlu, B. Collaborative or Simply Uncaged? Understanding Human-Cobot Interactions in Automation. In Proceedings of the $2020 \mathrm{CHI}$ Conference on Human Factors in Computing Systems, Honolulu, HI, USA, 21 April 2020; pp. 1-12.

67. Tucker, K.; Bulim, J.; Koch, G.; North, M.M. Internet industry: A perspective review through internet of things and internet of everything. Int. Manag. Rev. 2018, 14, 26.

68. Aazam, M.; Zeadally, S.; Harras, K.A. Deploying fog computing in industrial internet of things and industry 4.0. IEEE Trans. Ind. Inform. 2018, 14, 4674-4682. [CrossRef]

69. Wan, J.; Tang, S.; Shu, Z.; Li, D.; Wang, S.; Imran, M.; Vasilakos, A.V. Software-defined industrial internet of things in the context of industry 4.0. IEEE Sens. J. 2016, 16, 7373-7380. [CrossRef]

70. Hylving, L.; Schultze, U. Evolving the modular layered architecture in digital innovation: The case of the car's instrument cluster. In Proceedings of the International Conference on Information Systems (ICIS 2013), Milan, Italy, 15-18 December 2013; p. 13.

71. Kiel, D.; Müller, J.M.; Arnold, C.; Voigt, K.I. Sustainable industrial value creation: Benefits and challenges of industry 4.0. Int. J. Innov. Manag. 2017, 21, 1740015. [CrossRef]

72. Cheng, J.; Chen, W.; Tao, F.; Lin, C.L. Industrial IoT in 5G environment towards smart manufacturing. J. Ind. Inf. Integr. 2018, 10, 10-19. [CrossRef] 
73. Lee, J.; Kao, H.A.; Yang, S. Service innovation and smart analytics for industry 4.0 and big data environment. Procedia Cirp 2014, 16, 3-8. [CrossRef]

74. Raghupathi, W.; Raghupathi, V. Big data analytics in healthcare: Promise and potential. Health Inf. Sci. Syst. 2014, 2, 3. [CrossRef]

75. Babiceanu, R.F.; Seker, R. Big Data and virtualization for manufacturing cyber-physical systems: A survey of the current status and future outlook. Comput. Ind. 2016, 81, 128-137. [CrossRef]

76. Mell, P.G.; Grance, T. The NIST Definition of Cloud Computing; NIST Special Publication: Gaithersburg, MD, USA, 2011.

77. Varghese, B.; Buyya, R. Next generation cloud computing: New trends and research directions. Future Gener. Comput. Syst. 2018, 79, 849-861. [CrossRef]

78. Singh, A.; Chatterjee, K. Cloud security issues and challenges: A survey. J. Netw. Comput. Appl. 2017, 79, 88-115. [CrossRef]

79. He, W.; Xu, L. A state-of-the-art survey of cloud manufacturing. Int. J. Comput. Integr. Manuf. 2015, 28, 239-250. [CrossRef]

80. Ooi, K.B.; Lee, V.H.; Tan, G.W.H.; Hew, T.S.; Hew, J.J. Cloud computing in manufacturing: The next industrial revolution in Malaysia? Expert Syst. Appl. 2018, 93, 376-394. [CrossRef]

81. Available online: https://www.nytimes.com/2018/09/28/technology/facebook-hack-data-breach.html (accessed on 24 May 2020).

82. Available online: https://www.theguardian.com/uk-news/2020/jan/04/cambridge-analytica-data-leak-globalelection-manipulation (accessed on 24 May 2020).

83. Available online: https://www.iso.org/isoiec-27001-information-security.html (accessed on 24 May 2020).

84. Shafiq, S.I.; Sanin, C.; Szczerbicki, E.; Toro, C. Virtual engineering object/virtual engineering process: A specialized form of cyber physical system for Industrie 4.0. Procedia Comput. Sci. 2015, 60, 1146-1155. [CrossRef]

85. Available online: https://www.i-scoop.eu/industry-4-0/ (accessed on 24 May 2020).

86. Gunal, M.M. (Ed.) Simulation for Industry 4.0: Past, Present, and Future; Springer: Cham, Switzerland, 2019.

87. Gunes, V.; Peter, S.; Givargis, T.; Vahid, F. A survey on concepts, applications, and challenges in cyber-physical systems. KSII Trans. Internet Inf. Syst. 2014, 8, 4242-4268.

88. Lee, J.; Bagheri, B.; Kao, H.A. A cyber-physical systems architecture for industry 4.0-based manufacturing systems. Manuf. Lett. 2015, 3, 18-23. [CrossRef]

89. Jiang, J.R. An improved cyber-physical systems architecture for Industry 4.0 smart factories. Adv. Mech. Eng. 2018, 10, 1687814018784192. [CrossRef]

90. Lee, J.; Jin, C.; Bagheri, B. Cyber physical systems for predictive production systems. Prod. Eng. 2017, 11, 155-165. [CrossRef]

91. Humayed, A.; Lin, J.; Li, F.; Luo, B. Cyber-physical systems security-A survey. IEEE Internet Things J. 2017, 4, 1802-1831. [CrossRef]

92. Alcácer, V.; Cruz-Machado, V. Scanning the industry 4.0: A literature review on technologies for manufacturing systems. Eng. Sci. Technol. Int. J. 2019, 22, 899-919. [CrossRef]

93. Lee, E.A. Cyber physical systems: Design challenges. In Proceedings of the 2008 11th IEEE International Symposium on Object and Component-Oriented Real-Time Distributed Computing (ISORC), Orlando, FL, USA, 5-7 May 2008; pp. 363-369.

94. Barbosa, J.; Leitão, P.; Trentesaux, D.; Colombo, A.W.; Karnouskos, S. Cross benefits from cyber-physical systems and intelligent products for future smart industries. In Proceedings of the 2016 IEEE 14th International Conference on Industrial Informatics (INDIN), Poitiers, France, 19-21 July 2016; pp. 504-509.

95. Thoben, K.D.; Wiesner, S.; Wuest, T. "Industrie 4.0" and smart manufacturing-a review of research issues and application examples. Int. J. Autom. Technol. 2017, 11, 4-16. [CrossRef]

96. Lee, J.; Bagheri, B.; Jin, C. Introduction to cyber manufacturing. Manuf. Lett. 2016, 8, 11-15. [CrossRef]

97. Available online: https://mxdusa.org/ (accessed on 24 May 2020).

98. Zwolenski, M.; Weatherill, L. The digital universe: Rich data and the increasing value of the internet of things. J. Telecommun. Digit. Econ. 2014, 2, 47. [CrossRef]

99. Rong, H. Securing Manufacturing Computing and Controller Assets. Instrum. Stand. Metrol. 2010, 4, 16.

100. Buxmann, P.; Hess, T.; Ruggaber, R. Internet of services. Bus. Inf. Syst. Eng. 2009, 1, 341. [CrossRef] 
101. Mabkhot, M.M.; Al-Ahmari, A.M.; Salah, B.; Alkhalefah, H. Requirements of the smart factory system: A survey and perspective. Machine 2018, 6, 23. [CrossRef]

102. Wang, L. Cyber manufacturing: Research and applications. In Proceedings of the Tenth International Symposium on Tools and Methods of Competitive Engineering, TMCE, Budapest, Hungary, 19-23 May 2014; pp. 19-23.

103. Wang, L.; Törngren, M.; Onori, M. Current status and advancement of cyber-physical systems in manufacturing. J. Manuf. Syst. 2015, 37, 517-527. [CrossRef]

104. Gilchrist, A. Industry 4.0: The Industrial Internet of Things; Apress: Berkeley, CA, USA, 2016.

105. Ghobakhloo, M.; Azar, A. Business excellence via advanced manufacturing technology and lean-agile manufacturing. J. Manuf. Technol. Manag. 2018, 29, 2-24. [CrossRef]

106. Schlick, J.; Stephan, P.; Loskyll, M.; Lappe, D. Industrie 4.0 in der praktischen Anwendung. In Industrie 4.0 in Produktion, Automatisierung und Logistik; Springer: Wiesbaden, Germany, 2014; pp. 57-84.

107. Gupta, P. Modularity enablers: A tool for Industry 4.0. Life Cycle Reliab. Saf. Eng. 2019, 8, 157-163. [CrossRef]

108. Lucke, D.; Constantinescu, C.; Westkämper, E. Smart Factory-A Step towards the Next Generation of Manufacturing. In Manufacturing Systems and Technologies for the New Frontier; Mitsuishi, M., Ueda, K., Kimura, F., Eds.; Springer: London, UK, 2008; pp. 115-118.

109. Perales, D.P.; Valero, F.A.; García, A.B. Industry 4.0: A classification scheme. In Closing the Gap Between Practice and Research in Industrial Engineering; Viles, E., Ormazábal, M., Lleó, A., Eds.; Springer International Publishing: Cham, Switzerland, 2018; pp. 343-350.

110. Available online: https://www.rmit.edu.au/industry/develop-your-workforce/tailored-workforce-solutions/ c4de/articles/industry-40-design-principles (accessed on 24 May 2020).

111. Lu, Y. Industry 4.0: A survey on technologies, applications and open research issues. J. Ind. Inf. Integr. 2017, 6, 1-10. [CrossRef]

112. Shariat Zadeh, N.; Lundholm, T.; Lindberg, L.; Franzén Sivard, G. Integration of digital factory with smart factory based on Internet of Things. In Proceedings of the 26th CIRP Design Conference 2016, KTH Royal Institute of Technology, Stockholm, Sweden, 15-17 June 2016; Elsevier: Amsterdam, The Netherlands, 2016; Volume 50, pp. 512-517.

113. Lasi, H.; Fettke, P.; Kemper, H.G.; Feld, T.; Hoffmann, M. Industry 4.0. Bus. Inf. Syst. Eng. 2014, 6, $239-242$. [CrossRef]

114. Shamim, S.; Cang, S.; Yu, H.; Li, Y. Examining the feasibilities of Industry 4.0 for the hospitality sector with the lens of management practice. Energies 2017, 10, 499. [CrossRef]

115. Tantik, E.; Anderl, R. Integrated data model and structure for the asset administration shell in industrie 4.0. Procedia Cirp 2017, 60, 86-91. [CrossRef]

116. Ruj, S.; Stojmenovic, M.; Nayak, A. Decentralized access control with anonymous authentication of data stored in clouds. IEEE Trans. Parallel Distrib. Syst. 2013, 25, 384-394. [CrossRef]

117. Moreno, A.; Velez, G.; Ardanza, A.; Barandiaran, I.; de Infante, Á.R.; Chopitea, R. Virtualisation process of a sheet metal punching machine within the Industry 4.0 vision. Int. J. Interact. Des. Manuf. 2017, 11, 365-373. [CrossRef]

118. Schleich, B.; Anwer, N.; Mathieu, L.; Wartzack, S. Shaping the digital twin for design and production engineering. CIRP Ann. 2017, 66, 141-144. [CrossRef]

119. Tao, F.; Qi, Q. New IT driven service-oriented smart manufacturing: Framework and characteristics. IEEE Trans. on Syst. Man Cybern. Syst. 2017, 49, 81-91. [CrossRef]

120. Schuh, G.; Stich, V.; Brosze, T.; Fuchs, S.; Pulz, C.; Quick, J.; Schürmeyer, M.; Bauhoff, F. High resolution supply chain management: Optimized processes based on self-optimizing control loops and real time data. Prod. Eng. 2011, 5, 433-442. [CrossRef]

121. Dorozhkin, D.V.; Vance, J.M.; Rehn, G.D.; Lemessi, M. Coupling of interactive manufacturing operations simulation and immersive virtual reality. Virtual Real. 2012, 16, 15-23. [CrossRef]

122. Nee, A.Y.; Ong, S.K. Virtual and augmented reality applications in manufacturing. IFAC Proc. Vol. 2013, 46, 15-26. [CrossRef]

123. Mujber, T.S.; Szecsi, T.; Hashmi, M.S. Virtual reality applications in manufacturing process simulation. J. Mater. Process. Technol. 2004, 155, 1834-1838. [CrossRef]

124. Kühn-Kauffeldt, M.; Böttcher, J. Open Source Augmented Reality Applications for Small Manufacturing Businesses. In Augmented Reality and Virtual Reality; Springer: Cham, Switzerland, 2020; pp. 243-251. 
125. Damiani, L.; Demartini, M.; Guizzi, G.; Revetria, R.; Tonelli, F. Augmented and virtual reality applications in industrial systems: A qualitative review towards the industry 4.0 era. IFAC-Pap. 2018, 51, 624-630. [CrossRef]

126. Thames, L.; Schaefer, D. Industry 4.0: An overview of key benefits, technologies, and challenges. In Cybersecurity for Industry 4.0; Springer: Cham, Switzerland, 2017; pp. 1-33.

127. Hofmann, E.; Rüsch, M. Industry 4.0 and the current status as well as future prospects on logistics. Comput. Ind. 2017, 89, 23-34. [CrossRef]

128. Longo, F.; Nicoletti, L.; Padovano, A. Smart operators in industry 4.0: A human-centered approach to enhance operators' capabilities and competencies within the new smart factory context. Comput. Ind. Eng. 2017, 113, 144-159. [CrossRef]

129. Fischer, T.; Gebauer, H.; Fleisch, E. Service Business Development; Cambridge University Press: Cambridge, UK, 2012.

130. Trappey, A.J.; Trappey, C.V.; Fan, C.Y.; Hsu, A.P.; Li, X.K.; Lee, I.J. IoT patent roadmap for smart logistic service provision in the context of Industry 4.0. J. Chin. Inst. Eng. 2017, 40, 593-602. [CrossRef]

131. Yao, X.; Jin, H.; Zhang, J. Towards a wisdom manufacturing vision. Int. J. Comput. Integr. Manuf. 2015, 28, 1291-1312. [CrossRef]

132. Von Rosing, M.; Von Scheel, H.; Scheer, A.W. The Complete Business Process Handbook: Body of Knowledge from Process Modeling to BPM; Morgan Kaufmann Elsevier: Burlington, MA, USA, 2014; Volume 1.

133. Kirchmer, M. High Performance through Business Process Management; Springer: West Chester, PA, USA, 2017.

134. Hitchner, E. Reengineering the Corporation: A Manifesto for Business Revolution. Natl. Prod. Rev. 1993, 12, 443-449. [CrossRef]

135. Hammer, M. Deep change. Harv. Bus. Revie 2004, 82, 84-93.

136. Chan, P.S.; Peel, D. Causes and impact of reengineering. Bus. Process Manag. J. 1998, 4, 44-55. [CrossRef]

137. Kallio, J.; Saarinen, T.; Salo, S.; Tinnilä, M.; Vepsäläinen, A.P. Drivers and tracers of business process changes. J. Strateg. Inf. Syst. 1999, 8, 125-142. [CrossRef]

138. Ponzi, L.; Koenig, M. Knowledge management: Another management fad. Inf. Res. 2002, 8, 145.

139. Ozcelik, Y. Do business process reengineering projects payoff? Evidence from the United States. Int. J. Proj. Manag. 2010, 28, 7-13. [CrossRef]

140. Qu, Y.; Ming, X.; Ni, Y.; Li, X.; Liu, Z.; Zhang, X.; Xie, L. An integrated framework of enterprise information systems in smart manufacturing system via business process reengineering. Proc. Inst. Mech. Eng. Part B J. Eng. Manuf. 2019, 233, 2210-2224. [CrossRef]

141. Zur Muehlen, M.; Indulska, M. Modeling languages for business processes and business rules: A representational analysis. Inf. Syst. 2010, 35, 379-390. [CrossRef]

142. Rosemann, M.; vom Brocke, J. The six core elements of business process management. In Handbook on Business Process Management 1; Springer: Berlin/Heidelberg, Germany, 2015; pp. 105-122.

143. Conger, S. Six sigma and business process management. In Handbook on Business Process Management 1; Springer: Berlin/Heidelberg, Germany, 2015; pp. 127-146.

144. Vermesan, O.; Friess, P.; Guillemin, P.; Gusmeroli, S.; Sundmaeker, H.; Bassi, A.; Jubert, I.S.; Mazura, M.; Harrison, M.; Eisenhauer, M.; et al. Internet of things strategic research roadmap. Internet Things-Glob. Technol. Soc. Trend 2011, 1, 9-52.

145. Fischer, L. BPM Everywhere: Internet of Things, Process of Everything; Future Strategies: Lighthouse Point, FL, USA, 2015.

146. Del Giudice, M. Discovering the Internet of Things (IoT) within the business process management: A literature review on technological revitalization. Bus. Proc. Manag. J. 2016, 22, 263-270. [CrossRef]

147. Telukdarie, A. Business Processes: A critical tool for Industry 4.0 enablement. In Proceedings of the 2019 International Conference on Fourth Industrial Revolution (ICFIR), Manama, Bahrain, 19-21 February 2019; pp. 1-5.

148. Schoenthaler, F.; Augenstein, D.; Karle, T. Design and governance of collaborative business processes in industry 4.0. In Proceedings of the Workshop on Cross-Organizational and Cross-Company BPM (XOC-BPM) Co-Located with the 17th IEEE Conference on Business Informatics (CBI 2015), Lisbon, Portugal, 13-16 July 2015; p. 7.

149. Tupa, J.; Steiner, F. Industry 4.0 and business process management. Tech. Gaz. 2019, 13, 349-355. [CrossRef] 
150. Rehse, J.R.; Dadashnia, S.; Fettke, P. Business process management for Industry 4.0-three application cases in the DFKI-smart-lego-factory. it-Inf. Technol. 2018, 60, 133-141. [CrossRef]

151. Grefen, P.; Ludwig, H.; Tata, S.; Dijkman, R.; Baracaldo, N.; Wilbik, A.; D’hondt, T. September. Complex collaborative physical process management: A position on the trinity of BPM, IoT and DA. In Working Conference on Virtual Enterprises; Springer: Cham, Switzerland, 2018; pp. 244-253.

152. Secundo, G.; Toma, A.; Schiuma, G.; Passiante, G. Knowledge transfer in open innovation. Bus. Process Manag. J. 2019, 25, 144-163. [CrossRef]

153. Christenson, J.K.; O’Kane, G.M.; Farmery, A.K.; McManus, A. The barriers and drivers of seafood consumption in Australia: A narrative literature review. Int. J. Consum. Stud. 2017, 41, 299-311. [CrossRef]

154. Neumann, F. Antecedents and effects of emotions in strategic decision-making: A literature review and conceptual model. Manag. Rev. Q. 2017, 67, 175-200. [CrossRef]

155. de Camargo Fiorini, P.; Jabbour, C.J.C. Information systems and sustainable supply chain management towards a more sustainable society: Where we are and where we are going. Int. J. Inf. Manag. 2017, 37, 241-249. [CrossRef]

156. Viriyasitavat, W.; Da Xu, L.; Bi, Z.; Sapsomboon, A. Blockchain-based business process management (BPM) framework for service composition in industry 4.0. J. Intell. Manuf. 2018, 1-12. [CrossRef]

157. Xu, L.D.; Xu, E.L.; Li, L. Industry 4.0: State of the art and future trends. Int. J. Prod. Res. 2018, 56, $2941-2962$. [CrossRef]

158. Hitpass, B.; Astudillo, H. Industry 4.0 challenges for business process management and electronic-commerce. J. Theor. Appl. Electron. Commer. Res. 2019, 14, I-III. [CrossRef]

159. Chiu, Y.C.; Cheng, F.T.; Huang, H.C. Developing a factory-wide intelligent predictive maintenance system based on Industry 4.0. J. Chin. Inst. Eng. 2017, 40, 562-571. [CrossRef]

160. Wortmann, A.; Combemale, B.; Barais, O. A systematic mapping study on modeling for industry 4.0. In Proceedings of the 2017 ACM/IEEE 20th International Conference on Model Driven Engineering Languages and Systems (MODELS), Austin, TX, USA, 17-22 September 2017; pp. 281-291.

161. Telukdarie, A.; Buhulaiga, E.; Bag, S.; Gupta, S.; Luo, Z. Industry 4.0 implementation for multinationals. Process Saf. Environ. Prot. 2018, 118, 316-329. [CrossRef]

162. Tonelli, F.; Demartini, M.; Loleo, A.; Testa, C. A novel methodology for manufacturing firms value modeling and mapping to improve operational performance in the industry 4.0 era. Procedia CIRP 2016, 57, 122-127. [CrossRef]

163. Saraeian, S.; Shirazi, B.; Motameni, H. Towards an extended BPMS prototype: Open challenges of BPM to flexible and robust orchestrate of uncertain processes. Comput. Stand. Interface 2018, 57, 1-19. [CrossRef]

164. Kannengiesser, U.; Müller, H. Industry 4.0 Standardisation: Where Does S-BPM Fit? In Proceedings of the 10th International Conference on Subject-Oriented Business Process Management, Linz, Austria, 5 April 2018; pp. 1-8.

165. Available online: https://www.ntuclearninghub.com/mapping-the-mind-of-worker-4-0/ (accessed on 24 May 2020).

166. Romero, D.; Bernus, P.; Noran, O.; Stahre, J.; Fast-Berglund, Å. The operator 4.0: Human cyber-physical systems \& adaptive automation towards human-automation symbiosis work systems. In IFIP International Conference on Advances in Production Management Systems; Springer: Cham, Switzerland, 2016; pp. 677-686.

167. Segura, Á.; Diez, H.V.; Barandiaran, I.; Arbelaiz, A.; Álvarez, H.; Simões, B.; Posada, J.; García-Alonso, A.; Ugarte, R. Visual computing technologies to support the Operator 4.0. Comput. Ind. Eng. 2020, 139, 105550. [CrossRef]

168. Romero, D.; Stahre, J.; Wuest, T.; Noran, O.; Bernus, P.; Fast-Berglund, Å.; Gorecky, D. Towards an operator 4.0 typology: A human-centric perspective on the fourth industrial revolution technologies. In Proceedings of the International Conference on Computers and Industrial Engineering (CIE46), Tianjin, China, 29-31 October 2016; pp. 29-31.

169. Ruppert, T.; Jaskó, S.; Holczinger, T.; Abonyi, J. Enabling technologies for operator 4.0: A survey. Appl. Sci. 2018, 8, 1650. [CrossRef]

170. Romero, D.; Wuest, T.; Stahre, J.; Gorecky, D. Social factory architecture: Social networking services and production scenarios through the social internet of things, services and people for the social operator 4.0. In IFIP International Conference on Advances in Production Management Systems; Springer: Cham, Switzerland, 2017; pp. 265-273. 
171. Kaasinen, E.; Schmalfuß, F.; Özturk, C.; Aromaa, S.; Boubekeur, M.; Heilala, J.; Heikkilä, P.; Kuula, T.; Liinasuo, M.; Mach, S.; et al. Empowering and engaging industrial workers with Operator 4.0 solutions. Comput. Ind. Eng. 2020, 139, 105678. [CrossRef]

172. Mattsson, S.; Fast-Berglund, Å.; Li, D.; Thorvald, P. Forming a cognitive automation strategy for Operator 4.0 in complex assembly. Comput. Ind. Eng. 2020, 139, 105360. [CrossRef]

173. Tupa, J.; Simota, J.; Steiner, F. Aspects of risk management implementation for Industry 4.0. Procedia Manuf. 2017, 11, 1223-1230. [CrossRef]

174. Niesen, T.; Houy, C.; Fettke, P.; Loos, P. Towards an integrative big data analysis framework for data-driven risk management in industry 4.0. In Proceedings of the 2016 49th Hawaii International Conference on System Sciences (HICSS), Koloa, HI, USA, 5-8 January 2016; pp. 5065-5074.

175. Schröder, M.; Indorf, M.; Kersten, W. Industry 4.0 and its impact on supply chain risk management. In Proceedings of the 14th International Conference "Reliability and Statistics in Transportation and Communication", Riga, Latvia, 15-18 October 2014; pp. 114-125.

176. Ivanov, D.; Dolgui, A.; Sokolov, B. The impact of digital technology and Industry 4.0 on the ripple effect and supply chain risk analytics. Int. J. Prod. Res. 2019, 57, 829-846. [CrossRef]

177. Leonhardt, F.; Wiedemann, A. Realigning Risk Management in the Light of Industry 4.0; SSRN: Amsterdam, The Netherlands, 2015.

178. Birkel, H.S.; Veile, J.W.; Müller, J.M.; Hartmann, E.; Voigt, K.I. Development of a risk framework for Industry 4.0 in the context of sustainability for established manufacturers. Sustainability 2019, 11, 384. [CrossRef]

179. Badri, A.; Boudreau-Trudel, B.; Souissi, A.S. Occupational health and safety in the industry 4.0 era: A cause for major concern? Saf. Sci. 2018, 109, 403-411. [CrossRef]

180. Bonekamp, L.; Sure, M. Consequences of Industry 4.0 on human labour and work organisation. J. Bus. Media Psychol. 2015, 6, 33-40.

181. de Sousa Jabbour, A.B.L.; Jabbour, C.J.C.; Foropon, C.; Godinho Filho, M. When titans meet-Can industry 4.0 revolutionise the environmentally-sustainable manufacturing wave? The role of critical success factors. Technol. Forecast. Soc. Chang 2018, 132, 18-25. [CrossRef]

182. Glas, A.H.; Kleemann, F.C. The impact of industry 4.0 on procurement and supply management: A conceptual and qualitative analysis. Int. J. Bus. Manag. Invent. 2016, 5, 55-66.

183. Trstenjak, M.; Cosic, P. Process planning in Industry 4.0 environment. Procedia Manuf. 2017, 11, $1744-1750$. [CrossRef]

184. Gilchrist, A. Introducing Industry 4.0. In Industry 4.0; Apress: Berkeley, CA, USA, 2016; pp. 195-215.

185. Hecklau, F.; Galeitzke, M.; Flachs, S.; Kohl, H. Holistic approach for human resource management in Industry 4.0. Procedia Cirp 2016, 54, 1-6. [CrossRef]

186. Schneider, P. Managerial challenges of Industry 4.0: An empirically backed research agenda for a nascent field. Rev. Manag. Sci. 2018, 12, 803-848. [CrossRef]

187. Prifti, L.; Knigge, M.; Kienegger, H.; Krcmar, H. A Competency Model for “Industrie 4.0" Employees. In Proceedings of the der 13. Internationalen Tagung Wirtschaftsinformatik (WI 2017), St. Gallen, Bodensee, Switzerland, 12-15 February 2017; pp. 46-60.

188. Schallock, B.; Rybski, C.; Jochem, R.; Kohl, H. Learning Factory for Industry 4.0 to provide future skills beyond technical training. Procedia Manuf. 2018, 23, 27-32. [CrossRef]

189. Akdil, K.Y.; Ustundag, A.; Cevikcan, E. Maturity and readiness model for industry 4.0 strategy. In Industry 4.0: Managing the Digital Transformation; Springer: Cham, Switzerland, 2018; pp. 61-94.

190. Rao, S.K.; Prasad, R. Impact of 5G technologies on industry 4.0. Wirel. Pers. Commun. 2018, 100, 145-159. [CrossRef]

191. Brettel, M.; Friederichsen, N.; Keller, M.; Rosenberg, M. How virtualization, decentralization and network building change the manufacturing landscape: An Industry 4.0 Perspective. Int. J. Mech. Ind. Sci. Eng. 2014, 8, 37-44.

192. de Man, J.C.; Strandhagen, J.O. An Industry 4.0 research agenda for sustainable business models. Procedia Cirp 2017, 63, 721-726. [CrossRef]

193. Schröder, C. The Challenges of Industry 4.0 for Small and Medium-Sized Enterprises; Friedrich-Ebert-Stiftung: Bonn, Germany, 2016.

194. Agrawal, A.; Schaefer, S.; Funke, T. Incorporating Industry 4.0 in Corporate Strategy. In Analyzing the Impacts of Industry 4.0 in Modern Business Environments; IGI global: Hershey, PA, USA, 2018; pp. 161-176. 
195. Jayaram, A. Lean six sigma approach for global supply chain management using industry 4.0 and IIoT. In Proceedings of the 2016 2nd International Conference on Contemporary Computing and Informatics (IC3I), Noida, India, 14-17 December 2016; pp. 89-94.

196. Buer, S.V.; Strandhagen, J.O.; Chan, F.T. The link between Industry 4.0 and lean manufacturing: Mapping current research and establishing a research agenda. Int. J. Prod. Res. 2018, 56, 2924-2940.

197. Davies, R.; Coole, T.; Smith, A. Review of socio-technical considerations to ensure successful implementation of Industry 4.0. Procedia Manuf. 2017, 11, 1288-1295.

198. Arcidiacono, G.; Pieroni, A. The Revolution Lean Six Sigma 4.0. Int. J. Adv. Sci. Eng. Inf. Technol. 2018, 8, 141-149.

199. Rüttimann, B.G.; Stöckli, M.T. Lean and Industry 4.0-twins, partners, or contenders? A due clarification regarding the supposed clash of two production systems. J. Serv. Sci. Manag. 2016, 9, 485-500. [CrossRef]

200. Vancil, R.F.; Lorange, P. Strategic planning in diversified companies. Harv. Bus. Rev. 1975, 53, 81-90.

201. Jackson, S.E.; Joshi, A.; Erhardt, N.L. Recent research on team and organizational diversity: SWOT analysis and implications. J. Manag. 2003, 29, 801-830.

202. Daum, M.; Götz, M.; Domaschka, J. Integrating CEP and BPM: How CEP realizes functional requirements of BPM applications (industry article). In Proceedings of the 6th ACM International Conference on Distributed Event-Based Systems, Berlin, Germany, 16 July 2012; pp. 157-166.

203. Pavlovski, C.J.; Zou, J. Non-Functional Requirements in Business Process Modeling. In Proceedings of the 5th Asia-Pacific Conference on Conceptual Modelling (APCCM2008), Wollongong, New South Wales, Australia, 22-25 January 2008; pp. 103-112.

204. Mouritsen, J.; Mahama, H.; Chua, W.F. 12 Actor-Network Theory and the Study of Inter-Organisational Network-Relations. Account. Netw. 2010, 7, 292.

205. Xue, H.; Mason, D.S. The changing stakeholder map of formula one grand prix in Shanghai. Eur. Sport Manag. Quart. 2011, 11, 371-395. [CrossRef]

206. Venkatraman, S.; Venkatraman, R. Process Innovation and Improvement Using Business Object-Oriented Process Modelling (BOOPM) Framework. Appl. Syst. Innov. 2019, 2, 23. [CrossRef]

207. Salgado, C.E.; Machado, R.J.; Maciel, R.S. Using process-level use case diagrams to infer the business motivation model with a RUP-based approach. In Information System Development; Springer: Cham, Switzerland, 2014; pp. 123-134.

208. Available online: https://medium.com/pm101/8-flowcharts-and-diagrams-apps-837373859e87 (accessed on 26 April 2020).

209. Wohed, P.; van der Aalst, W.M.; Dumas, M.; ter Hofstede, A.H.; Russell, N. On the suitability of BPMN for business process modelling. In International Conference on Business Process Management; Springer: Berlin/Heidelberg, Germany, 2006; pp. 161-176.

210. Meudt, T.; Metternich, J.; Abele, E. Value stream mapping 4.0: Holistic examination of value stream and information logistics in production. Cirp Ann. 2017, 66, 413-416. [CrossRef]

211. Bauer, K. KPIs-The metrics that drive performance management. Inf. Manag. 2004, 14, 63.

212. Bauer, K. KPIs: Not all metrics are created equal. Inf. Manag. 2004, 14, 42.

213. Davies, J.; Haubenstock, M. Building effective indicators to monitor operational risk. RMA J. 2002, 84, 40-43.

214. Scandizzo, S. Risk mapping and key risk indicators in operational risk management. Econ. Note 2005, 34, 231-256. [CrossRef]

215. Davies, J.; Finlay, M.; McLenaghen, T.; Wilson, D. Key risk indicators-their role in operational risk management and measurement. ARM Risk Bus. Int. Prague 2006, 1-32. Available online: http://citeseerx.ist.psu.edu/ viewdoc/download?doi=10.1.1.457.893\&rep=rep1\&type=pdf (accessed on 26 April 2020).

216. Rosenberg, A.; Chase, G.; Omar, R.; Taylor, J.; von Rosing, M. Applying Real-World BPM in an SAP Environment; Galileo Press: Cambridge, UK, 2011.

217. Brundage, M.P.; Bernstein, W.Z.; Morris, K.C.; Horst, J.A. Using graph-based visualizations to explore key performance indicator relationships for manufacturing production systems. Procedia Cirp 2017, 61, 451-456. [CrossRef]

218. Available online: https://opsdog.com/resources/key-risk-indicators-examples-kris-technology-riskmanagement/ (accessed on 26 April 2020). 
219. Del-Río-Ortega, A.; Resinas, M.; Ruiz-Cortés, A. October. Defining process performance indicators: An ontological approach. In OTM Confederated International Conferences "On the Move to Meaningful Internet Systems"; Springer: Berlin/Heidelberg, Germany, 2010; pp. 555-572.

220. Available online: https://www.minit.io/blog/5-critical-process-performance-indicators-and-how-processmining-can-help-you-track-them (accessed on 26 April 2020).

221. Del-RíO-Ortega, A.; Resinas, M.; Cabanillas, C.; Ruiz-Cortés, A. On the definition and design-time analysis of process performance indicators. Inf. Syst. 2013, 38, 470-490. [CrossRef]

222. Thompson, J.D. Organizations in Action: Social Science Bases of Administrative Theory; Transaction Publishers: Piscataway, NJ, USA, 2003.

223. Available online: https://www.samewave.com/posts/understand-the-three-types-of-task-interdependenceand-why-they-matter (accessed on 26 April 2020).

224. Khan, M.A.A.; Butt, J.; Mebrahtu, H.; Shirvani, H.; Sanaei, A.; Alam, M.N. Integration of Data-Driven Process Re-Engineering and Process Interdependence for Manufacturing Optimization Supported by Smart Structured Data. Design 2019, 3, 44. [CrossRef]

225. Modarress, B.; Ansari, A.; Lockwood, D.L. Kaizen costing for lean manufacturing: A case study. Int. J. Prod. Res. 2005, 43, 1751-1760. [CrossRef]

226. Akay, D.; Demiray, A.; Kurt, M. Collaborative tool for solving human factors problems in the manufacturing environment: The Theory of Inventive Problem Solving Technique (TRIZ) method. Int. J. Prod. Res. 2008, 46, 2913-2925. [CrossRef]

227. Butt, J.; Jedi, S. Redesign of an In-Market Conveyor System for Manufacturing Cost Reduction and Design Efficiency Using DFMA Methodology. Designs 2020, 4, 6. [CrossRef]

228. Lee, J.; Lapira, E.; Bagheri, B.; Kao, H.A. Recent advances and trends in predictive manufacturing systems in big data environment. Manuf. Lett. 2013, 1, 38-41. [CrossRef]

229. Lee, J.; Ardakani, H.D.; Yang, S.; Bagheri, B. Industrial big data analytics and cyber-physical systems for future maintenance \& service innovation. Procedia Cirp 2015, 38, 3-7.

230. Weyer, S.; Schmitt, M.; Ohmer, M.; Gorecky, D. Towards Industry 4.0-Standardization as the crucial challenge for highly modular, multi-vendor production systems. IFAC-Pap. 2015, 48, 579-584. [CrossRef]

231. Truong, H.Q.; Hara, Y. Supply chain risk management: Manufacturing-and service-oriented firms. J. Manuf. Technol. Manag. 2018, 29, 218-239.

232. Available online: https://simplicable.com/new/risk-management-vs-contingency-planning (accessed on 29 April 2020).

233. Ruiz-Torres, A.J.; Mahmoodi, F.; Zeng, A.Z. Supplier selection model with contingency planning for supplier failures. Comput. Ind. Eng. 2013, 66, 374-382. [CrossRef]

234. Castelo-Branco, I.; Cruz-Jesus, F.; Oliveira, T. Assessing Industry 4.0 readiness in manufacturing: Evidence for the European Union. Comput. Ind. 2019, 107, 22-32. [CrossRef]

235. Samaranayake, P.; Ramanathan, K.; Laosirihongthong, T. Implementing industry 4.0-A technological readiness perspective. In Proceedings of the 2017 IEEE International Conference on Industrial Engineering and Engineering Management (IEEM), Singapore, 10-13 December 2017; pp. 529-533.

236. Mittelmann, A. Competence development for Work 4.0. In Knowledge Management in Digital Change; Springer: Cham, Switzerland, 2018; pp. 263-275.

237. Beckett, R.; Daberkow, T. Work 4.0 and the Need for Boundary-Spanning. J. World Bus. 2020, 5, $28-2020$.

238. Karacay, G. Talent development for Industry 4.0. In Industry 4.0: Managing the Digital Transformation; Springer: Cham, Switzerland, 2018; pp. 123-136.

239. Oztemel, E.; Gursev, S. Literature review of Industry 4.0 and related technologies. J. Intell. Manuf. 2020, 31, 127-182. [CrossRef]

240. Gentner, S. Industry 4.0: Reality, future or just science fiction? How to convince today's management to invest in tomorrow's future! Successful strategies for industry 4.0 and manufacturing IT. Chim. Int. J. Chem. 2016, 70, 628-633. [CrossRef]

241. Chen, H.; Chiang, R.H.; Storey, V.C. Business intelligence and analytics: From big data to big impact. MIS Q. 2012, 36, 1165-1188. [CrossRef]

242. Myers, K.; Berry, P.; Blythe, J.; Conley, K.; Gervasio, M.; McGuinness, D.L.; Morley, D.; Pfeffer, A.; Pollack, M.; Tambe, M. An intelligent personal assistant for task and time management. Ai Mag. 2007, 28, 47.

243. Available online: https://en.unesco.org/themes/futures-literacy (accessed on 25 May 2020). 
244. Todnem By, R. Organisational change management: A critical review. J. Chang. Manag. 2005, 5, 369-380.

245. Lorenzi, N.M.; Riley, R.T. Organizational issues= change. Int. J. Med. Inform. 2003, 69, 197-203. [CrossRef]

246. Bartik, A.W.; Bertrand, M.; Cullen, Z.B.; Glaeser, E.L.; Luca, M.; Stanton, C.T. How are Small Businesses Adjusting to COVID-19? Early Evidence from a Survey (No. w26989); National Bureau of Economic Research: Cambridge, MA, USA, 2020.

247. Available online: https://www.strategy-business.com/article/rr00006?gko=dab72 (accessed on 25 May 2020).

248. Hlupic, V.; Pouloudi, A.; Rzevski, G. Towards an integrated approach to knowledge management:'hard','soft'and 'abstract'issues. Knowl. Process Manag. 2002, 9, 90-102. [CrossRef]

249. Gill, R. Change management-or change leadership? J. Chang. Manag. 2002, 3, 307-318. [CrossRef]

250. Levasseur, R.E. People skills: Change management tools—Lewin's change model. Interface 2001, 31, 71-73.

251. Hussain, S.T.; Lei, S.; Akram, T.; Haider, M.J.; Hussain, S.H.; Ali, M. Kurt Lewin's change model: A critical review of the role of leadership and employee involvement in organizational change. J. Innov. Knowledg 2018, 3, 123-127. [CrossRef]

252. Hiatt, J. ADKAR: A Model for Change in Business, Government, and Our Community; Prosci Learning Center Publications: Loveland, CO, USA, 2006.

253. Boca, G.D. Adkar model VS. quality management change. In International Conference Risk in Contemporary Economy; Faculty of Economics and Business Administration, Dunarea de Jos University of Galati: Galati, Romania, 2013.

254. CHANGE, C.V. Technology Adoption: Managing Change. Prim. Psychiatry 2006, 13, $20-23$.

255. Ashkenas, R. Change management needs to change. Harv. Bus. Rev. 2013, 3, 20-23.

256. Welbourne, T.M. Change management needs a change. Employ. Relat. Toda 2014, 41, 17-23. [CrossRef]

257. Available online: https:/www.forbes.com/sites/forbestechcouncil/2019/06/18/change-management-needschange-management/\#687e91ab6656 (accessed on 25 May 2020).

258. Schmidt, R.; Möhring, M.; Härting, R.C.; Reichstein, C.; Neumaier, P.; Jozinović, P. Industry 4.0-potentials for creating smart products: Empirical research results. In International Conference on Business Information Systems; Springer: Cham, Switzerland, 2015; pp. 16-27.

259. Henderson, S.C.; Swamidass, P.M.; Byrd, T.A. Empirical models of the effect of integrated manufacturing on manufacturing performance and return on investment. Int. J. Prod. Res. 2004, 42, 1933-1954. [CrossRef]

260. Phillips, J.J.; Marston, M. Measuring ROI. Fad fact Fantasy 2007, 61, 42.

261. Phillips, J.J.; Phillips, P.P. Measuring ROI in executive coaching. Int. J. Coach. Organ. 2005, 3, 53-62.

262. Phillips, J.J.; Phillips, P. Using ROI to demonstrate performance value in the public sector. Perform. Improv. 2009, 48, 22-28. [CrossRef]

263. Phillips, J.J.; Phillips, P.P. Distinguishing ROI myths from reality. Perform. Improv. 2008, 47, 12-17. [CrossRef]

264. Boehm, B.; Huang, L.; Jain, A.; Madachy, R. The ROI of software dependability: The iDAVE model. IEEE Softw. 2004, 21, 54-61. [CrossRef]

265. Naim, M.M.; Wikner, J.; Grubbström, R.W. A net present value assessment of make-to-order and make-to-stock manufacturing systems. Omeg 2007, 35, 524-532. [CrossRef]

266. Available online: https://sixsigmastudyguide.com/pilot-plan/ (accessed on 30 April 2020).

267. Antony, J.; Kumar, M.; Labib, A. Gearing Six Sigma into UK manufacturing SMEs: Results from a pilot study. J. Oper. Res. Soc. 2008, 59, 482-493. [CrossRef]

268. Georgoulias, K.; Papakostas, N.; Chryssolouris, G.; Stanev, S.; Krappe, H.; Ovtcharova, J. Evaluation of flexibility for the effective change management of manufacturing organizations. Robot. Comput.-Integr. Manuf. 2009, 25, 888-893. [CrossRef]

269. Leach, L. Schedule and cost buffer sizing: How to account for the bias between project performance and your model. Proj. Manag. J. 2003, 34, 34-47. [CrossRef]

270. May, G.; Stahl, B. The significance of organizational change management for sustainable competitiveness in manufacturing: Exploring the firm archetypes. Int. J. Prod. Res. 2017, 55, 4450-4465. [CrossRef]

271. Rüßmann, M.; Lorenz, M.; Gerbert, P.; Waldner, M.; Justus, J.; Engel, P.; Harnisch, M. Industry 4.0: The future of productivity and growth in manufacturing industries. Boston Consult. Group 2015, 9, 54-89.

272. Harmon, P.; Trends, B.P. Business Process Change: A Guide for Business Managers and BPM and Six Sigma Professionals; Elsevier: Waltham, MA, USA, 2010; ISBN 978-0-12-374152-3. 
273. Skalle, H.; Hahn, B. Applying Lean, Six Sigma, BPM, and SOA to Drive Business Results; IBM Corporation: Armonk, NY, USA, 2013.

274. LaFollette, W.H. BPM, lean and six sigma-all together now. Lean Six Sigma Rev. 2015, 15, 23.

(C) 2020 by the author. Licensee MDPI, Basel, Switzerland. This article is an open access article distributed under the terms and conditions of the Creative Commons Attribution (CC BY) license (http://creativecommons.org/licenses/by/4.0/). 